\title{
Molecular-Based Identification of Actinomycetes Species That Synthesize Antibacterial Silver Nanoparticles
}

\author{
Abebe Bizuye (iD, ${ }^{1,2}$ Lashitew Gedamu, ${ }^{3}$ Christine Bii, ${ }^{4}$ Erastus Gatebe, ${ }^{5}$ \\ and Naomi Maina (iD) \\ ${ }^{1}$ Department of Medical Laboratory, College of Medicine and Health Sciences, Bahir Dar University, Bahir Dar, Ethiopia \\ ${ }^{2}$ Molecular Biology and Biotechnology, Pan African University Institute of Basic Sciences, Innovation and Technology, \\ Jomo Kenyatta University of Agriculture and Technology, Nairobi, Kenya \\ ${ }^{3}$ Department of Biological Sciences, University of Calgary, Calgary, Canada \\ ${ }^{4}$ Centre for Microbiology Research, Kenya Medical Research Institute, Nairobi, Kenya \\ ${ }^{5}$ Kenya Industrial Research Development and Innovation, Nairobi, Kenya \\ ${ }^{6}$ Department of Biochemistry, College of Health Sciences, Jomo Kenyatta University of Agriculture and Technology, \\ Nairobi, Kenya
}

Correspondence should be addressed to Abebe Bizuye; hiwotabebe2015@gmail.com

Received 18 August 2020; Revised 17 October 2020; Accepted 16 November 2020; Published 24 November 2020

Academic Editor: Diriba Muleta

Copyright (c) 2020 Abebe Bizuye et al. This is an open access article distributed under the Creative Commons Attribution License, which permits unrestricted use, distribution, and reproduction in any medium, provided the original work is properly cited.

\begin{abstract}
Infectious diseases caused by antibiotic-resistant bacteria lead to a considerable increase in human morbidity and mortality globally. This requires to search potential actinomycete isolates from undiscovered habitats as a source of effective bioactive metabolites and to synthesis metabolite-mediated antibacterial silver nanoparticles (AgNPs). The main purpose of the present study was to identify actinomycetes isolated from Thika waste dump soils that produce bioactive metabolites to synthesize antibacterial AgNPs. The synthesis of metabolite-mediated AgNP was confirmed with visual detection and a UV-vis spectrophotometer, whereas the functional groups involved in AgNP synthesis were identified using a FTIR spectrophotometer. The antibacterial activity of the metabolite-mediated AgNPs was tested by a well diffusion assay. Identification of actinomycete isolates involved in the synthesis of antibacterial AgNPs was done based on 16S rRNA gene sequence analysis. The visual detection showed that dark salmon and pale golden color change was observed due to the formation of AgNPs by KDT32 and KGT32 metabolites, respectively. The synthesis was confirmed by a characteristic UV spectra peak at $415.5 \mathrm{~nm}$ for KDT32-AgNP and $416 \mathrm{~nm}$ for KGT32-AgNP. The FTIR spectra revealed that $\mathrm{OH}, \mathrm{C}=\mathrm{C}$, and $\mathrm{S}-\mathrm{S}$ functional groups were involved in the synthesis of KDT32$\mathrm{AgNP}$, whereas $\mathrm{OH}, \mathrm{C}=\mathrm{C}$, and $\mathrm{C}-\mathrm{H}$ were involved in the formation of KGT32-AgNP. The inhibition zone results revealed that KDT32-AgNP showed $22.0 \pm 1.4 \mathrm{~mm}$ and $19.0 \pm 1.4 \mathrm{~mm}$ against Escherichia coli and Salmonella typhi, whereas KGT32-AgNP showed $21.5 \pm 0.7 \mathrm{~mm}$ and $17.0 \pm 0.0 \mathrm{~mm}$, respectively. KDT32 and KGT32 isolates were identified as genus Streptomyces and their $16 \mathrm{~S}$ rRNA gene sequences were deposited in the GenBank database with MH301089 and MH301090 accession numbers, respectively. Due to the bactericidal activity of synthesized AgNPs, KDT32 and KGT32 isolates can be used in biomedical applications.
\end{abstract}

\section{Introduction}

Bacteria are one of the common causative agents of infectious diseases that can be treated via antibiotics produced by secondary metabolite producing microorganisms. However, bacterial pathogens acquire resistance to antibacterial agents through misuse and abuse of these chemicals. Acquired resistance to antibacterial can occur either by chromosomal gene mutation or by horizontal gene transfer via transduction, conjugation, and transformation [1]. These decrease the entry of antibacterial and change the antibacterial targets and metabolic inactivation of antibacterial agents [1]. These 
increase human morbidity and mortality rates [2] with considerable impact on clinical and economic issues globally $[3,4]$.

Escherichia coli, Salmonella spp., Shigella spp., and Vibrio spp. are frequently occurring drug-resistant Gramnegative bacteria in the East Africa region [5]. Resistance to amoxicillin, trimethoprim-sulfamethoxazole, tetracycline, nalidixic acid, ceftriaxone, ciprofloxacin, and ofloxacin has been reported for E. coli isolates [6]. Salmonella spp. showed resistance against fluoroquinolones, ceftriaxone, ciprofloxacin, and azithromycin [7]. Moreover, most Shigella spp. isolated from children in the hospital showed resistance to tetracycline and trimethoprim-sulfamethoxazole [8], and this indicates the need for effective antibacterial agents.

With increasing drug-resistant pathogens against bulk antimicrobial agents, nanomedicine has attracted attention [9]. The biosorption, bioaccumulation, biomineralization, and biodetoxification natures of microorganisms make them potential nanofactories [10]. Bacteria, the main group of microorganisms, are potential sources of bioactive metabolites that synthesize antibacterial AgNPs [11]. Previous reports showed that actinomycetes can produce bioactive compounds that are capable of reducing silver salts to AgNPs [12]. They are sources of diverse groups of bioactive compounds capable of synthesizing antibacterial AgNPs [13-16]. In particular, the synthesis of AgNPs by bioactive metabolites from Streptomyces spp. showed antibacterial activity against E. coli and S. typhi [17-20].

Actinomycetes isolated from Ethiopian and Kenyan soils produced bioactive metabolites that showed antibacterial activity against E. coli, S. typhi, and S. boydii [21-25]. However, the status of the synthesis of antibacterial AgNP using bioactive metabolites produced by actinomycetes isolated from the East African region is limited. The soil of waste dump sites in this region is one of the unexplored areas. Such sites may contain diverse types of nutrients (carbon source, nitrogen source, minerals, and metals such as silver) so that various bioactive metabolite producing potential actinomycetes can be found. In addition, the probability of getting antibacterial metabolites producing actinomycetes that involve the bioreduction of metals such as silver is high. The main purpose of this study was to identify actinomycete isolates isolated from Thika waste dump soil (central part of Kenya) that produce bioactive metabolites for the synthesis of antibacterial AgNPs.

\section{Materials and Methods}

2.1. Test Bacterial Pathogens. Escherichia coli, Salmonella typhi, and Shigella boydii are human bacteria pathogens used to perform in vitro antibacterial susceptibility tests. They are clinical isolates obtained from KEMRI (Kenya Medical Research Institute, Mycology Laboratory).

\subsection{Bioactive Metabolites Preparation. KDT32 and KGT32} isolates that were isolated from composite soil samples collected from Kiganjo waste dump site in Thika, Central parts of Kenya, were used for bioactive metabolites preparation for this study. Selective isolation and bioassay-guided screening of KDT32 and KGT32 were previously described [22].

Metabolite preparation from isolates was done according to Składanowski et al. [26]. Cell-free supernatants (secondary bioactive metabolites) were prepared by centrifugation at $5000 \mathrm{rpm}$ for 25 minutes and filtration by $0.22 \mu \mathrm{m}$ pore size filter paper from 7-day-old cultures.

2.3. Synthesis of Silver Nanoparticles, Visual Detection, and $U V$-Visible Spectra Analysis. The synthesis of AgNPs was done according to Składanowski et al. [26]. A mixture $(1: 1)$ of metabolite solution and $10 \mathrm{mM}$ AgNO3 solution was prepared from silver nitrate solution (10 mM AgNO3 solution or $1.6987 \mathrm{~g} \mathrm{AgNO} / 1 \mathrm{~L}$ sterile distilled water) and incubated at $28^{\circ} \mathrm{C}$ for seven days.

The color change and absorption intensity measurement in the reaction solution at each reaction day interval was assessed through visual observation and using a 6800 double beam UV-visible spectrophotometer (Jenway, UK), respectively. UV-vis spectrophotometer was used to confirm the presence of a characteristic UV spectra peak between 400 and $500 \mathrm{~nm}$. The types of AgNPs synthesized by metabolites from KDT32 and KGT32 isolates were represented as KDT32-AgNP and KGT32-AgNP, respectively.

2.4. FTIR Spectra Analysis of Biomolecules Used for AgNPs Synthesis. The sample preparation for FTIR spectra analysis of metabolite-mediated AgNPs was done according to AbdElnaby et al. (2016) [17]. The synthesized AgNPs were filtered using $0.22 \mu \mathrm{m}$ pore size filter paper followed by centrifugation at $5000 \mathrm{rpm}$ for 25 minutes. The pellet was washed with sterile distilled water followed by centrifugation and the supernatant was discarded. This step was repeated three times to remove unbound metabolites from metabolite-mediated nanoparticles.

The pellets were put on potassium bromide $(\mathrm{KBr})$ discs and analyzed using FTIR spectrophotometer (Bruker alpha model, Germany) in transmittance mode in the range of $4000-400 \mathrm{~cm}^{-1}$ wavenumbers at $4 \mathrm{~cm}^{-1}$ resolution [27]. The results of FTIR spectra from both metabolites only and metabolite-mediated AgNPs were recorded for comparison of the band shape, band position, and band intensity change.

2.5. Testing of Antibacterial Activity of AgNPs. Both synthesized AgNPs (pellets) and the metabolites were freezedried to make a powder using a freeze dryer. The antibacterial activity of the metabolite-mediated AgNPs was evaluated by a well diffusion assay [10]. The pathogens (E. coli, $S$. typhi, and $S$. boydii) were grown overnight on Muller Hinton agar plates. The colonies were taken and suspended in $5 \mathrm{ml}$ sterile water in test tubes and adjusted to 0.5 McFarland turbidity standards [28]. The suspensions were swabbed on Muller Hinton agar plates. Stock solution ( $2 \mathrm{mg} /$ ml) was prepared from $\mathrm{AgNO}_{3}, \mathrm{KDT} 32-\mathrm{AgNPs}$, KGT32AgNPs, and metabolites of KDT32 and KGT32. Streptomycin $(0.1 \mathrm{mg} / \mathrm{ml})$ and water were used as a positive and negative control, respectively. From each solution, $80 \mu \mathrm{l}$ was 
added to each well, and the plates were incubated at $37^{\circ} \mathrm{C}$ for $18 \mathrm{hrs}$ to determine the inhibition zone.

2.6. Characterization of Isolates for Identification. Colony and cell morphology, catalase test, $\mathrm{pH}$, and salt concentration tolerance test were done according to previous reports [29]. The genomic DNA of KDT32 and KGT32 was extracted and purified by the QIAamp Mini kit according to the manufacturer's instruction [30]. Amplification of $16 \mathrm{~S}$ rRNA gene from genomic DNA of KDT32 and KGT32 isolates was done using 243F (5'-GGATGAGCCCGCGGCCTA- $\left.3^{\prime}\right)$ and A3R (5'-CCAGCCCCACCTTCGAC- $\left.3^{\prime}\right)$ primers as described previously [31]. The quality and integrity of the amplified gene product were confirmed by gel electrophoresis according to Chen et al. [32]. The gene product was sent to Macrogen (1105AZ Amsterdam, Netherlands) and sequenced according to the manufacturer's instructions.

The quality of the obtained sequence was checked, trimmed, and prepared using BioEdit software and MEGA 7 software to get a consensus sequence. The consensus $16 \mathrm{~S}$ rRNA gene sequence from both local isolates was submitted to GenBank to get GenBank accession number (http://www. ncbi.nlm.nih.gov/projects/Sequin/) using Sequin tool/program from NCBI web server [33].

Similarity search for consensus sequences was done using NCBI (https://blast.ncbi.nlm.nih.gov/) [32] and EzTaxon-e (http://eztaxon-e.ezbiocloud.net/) [34] database to get the closest reference sequences. The closest reference sequences obtained from the EzTaxon-e database were used for phylogenetic analysis using the MEGA 7 software package. Multiple sequence analysis for both reference sequences and sequences from local isolates was done using CLUSTAL W [32]. From these, character matrices and distance matrices were generated for maximum likelihood (ML) and neighbor-joining (NJ) tree construction, respectively. Neighbor joining and ML algorithm from the MEGA 7 software package were used to construct the phylogenetic tree. The tree topology (branching pattern) was validated by bootstrap values calculated by 1000 resampling replicates [32].

2.7. Data Analysis. The mean \pm standard deviation values of inhibition zone comparisons were performed using one-way ANOVA ranked with Tukey's multiple range test with descriptive analysis by SPSS version 20 . The differences were tested on $p<0.05$ (95\% probability level), and all statistical values at $p<0.05$ are statistically significantly different. The sequence similarity of KDT32 and KGT32 sequences with reference sequences was described using percentage. The taxonomic position of the isolates compared to the closest reference sequences was inferred by the construction of both character and distance matrices based on the phylogenetic tree and validated by bootstrap value.
2.8. Ethical Consideration. The antibacterial activity test was done in vitro against bacterial human pathogens available in KEMRI. These did not require any specific and strict permission.

\section{Results}

\subsection{Actinomycete Metabolite-Mediated Synthesis and Characterization of Antibacterial Silver Nanoparticles}

3.1.1. Visual Detection and UV-Visible Spectra Analysis of Metabolite-Mediated AgNPs. The visual and spectrophotometer detection confirmed that both KDT32 and KGT32 metabolites were successfully synthesized AgNPs (Figures 1-3). The formation of KDT32-AgNPs and KGT32-AgNPs was observed by a color change from straw to dark salmon (Figure 1(a)) and straw to a pale golden rod (Figure 1(b)), respectively.

The KDT32-AgNP and KGT32-AgNP represent a silver nanoparticle formed by KDT32 metabolite (produced by KDT32 isolate) and KGT32 metabolite (produced by KGT32 isolate), respectively.

As observed from Figures 2 and 3, there was no evidence of characteristic absorption peak scanned in the range of 400-500 $\mathrm{nm}$ by the reaction solution at the time of mixing and the controls (metabolite solution and $\mathrm{AgNO}_{3}$ solution) (Figures 2 and 3 ). However, the reaction solution of $\mathrm{KDT}_{32}-\mathrm{AgNO}_{3}$ and $\mathrm{KGT} 32-\mathrm{AgNO}_{3}$ exhibited a clear excitation or characteristic peak after a 5-day reaction (Figures 2 and 3).

The formation of KDT32-AgNP progressively increased the absorption intensity from 1.3872 to 1.6925 as the reaction time increases from 5 to 7 days, respectively (Figure 2). A clear characteristic peak formation was observed and centered at 411.5 and $415.5 \mathrm{~nm}$, respectively (Figure 2).

The KGT32-AgNPs formation also showed an increase in absorption intensity from 1.1331 to 1.3665 and decreased to 1.0114 as the reaction time increased from 5,6 to 7 days (Figure 3). The position of the maximum spectra peaks was also shown with a minor shift center at $413.5 \mathrm{~nm}, 416 \mathrm{~nm}$ to $416.5 \mathrm{~nm}$, respectively (Figure 3 ).

3.1.2. Identification of Biomolecules Used for AgNPs Synthesis Using FTIR. FTIR spectra results showed that KDT32 metabolites exhibited strong and medium absorption bands at different wavenumbers $(3774.79,3386.91,2090.27$, $1638.98,1396.67$, and $461.42 \mathrm{~cm}^{-1}$ ) (Figure 4). The medium and sharp band at $3774.79 \mathrm{~cm}^{-1}$ and the strong and broad band at $3386.91 \mathrm{~cm}^{-1}$ corresponded to the $\mathrm{O}-\mathrm{H}$ stretch. The medium band at $2090.27 \mathrm{~cm}^{-1}$ and the strong band at $1638.98 \mathrm{~cm}^{-1}$ represented -NCS (isothiocyanate) stretch and $\mathrm{C}=\mathrm{C}$ (alkenes) stretch, respectively. The medium band at $1396.67 \mathrm{~cm}^{-1}$ and the strong band at $461.42 \mathrm{~cm}^{-1}$ represent organic sulfate stretches and stretch of S-S, respectively.

The FTIR spectra of KDT32-AgNPs results showed a change in band position, intensity, and shape compared to the spectra of KDT32 metabolite (Figure 4). This suggests the 


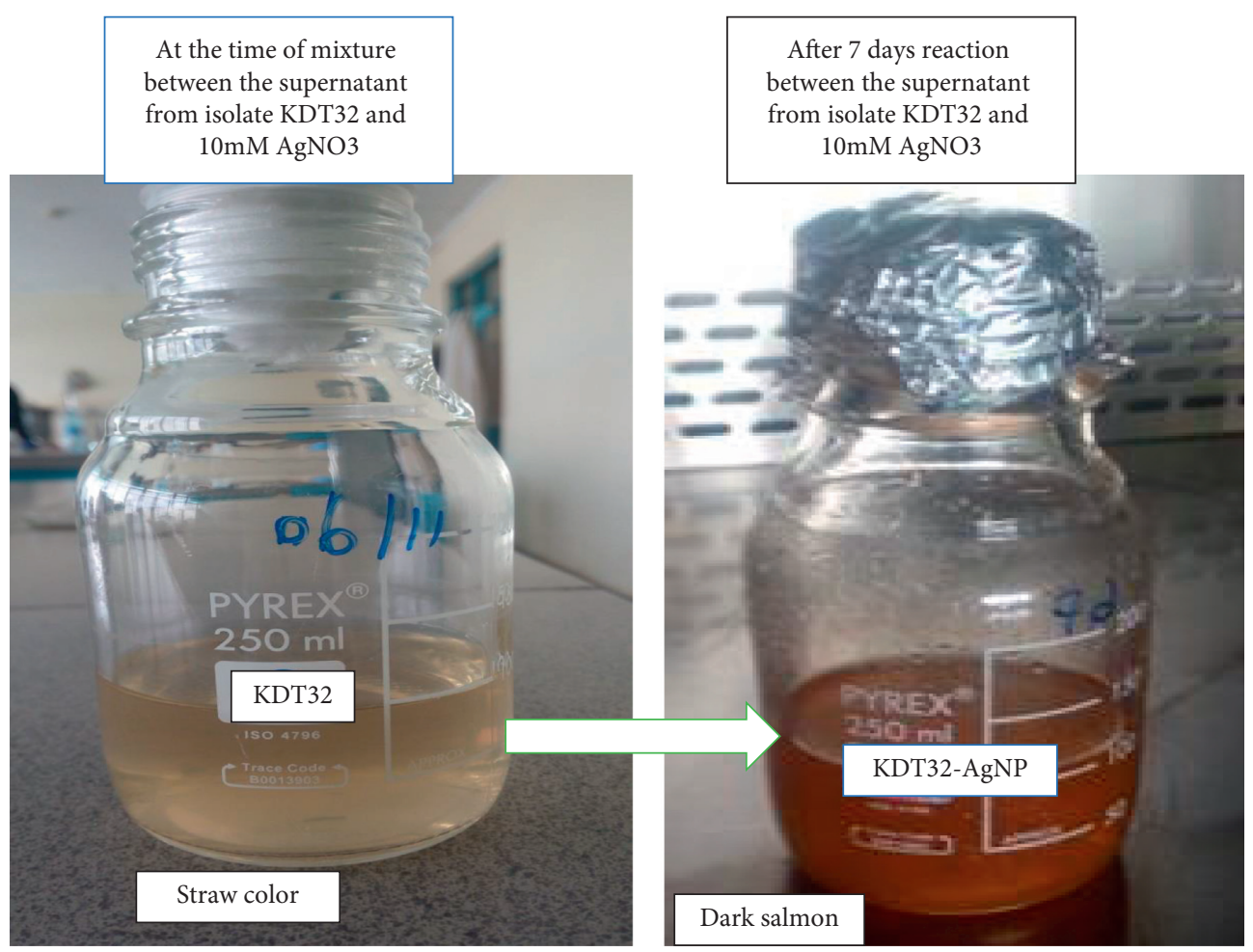

(a)

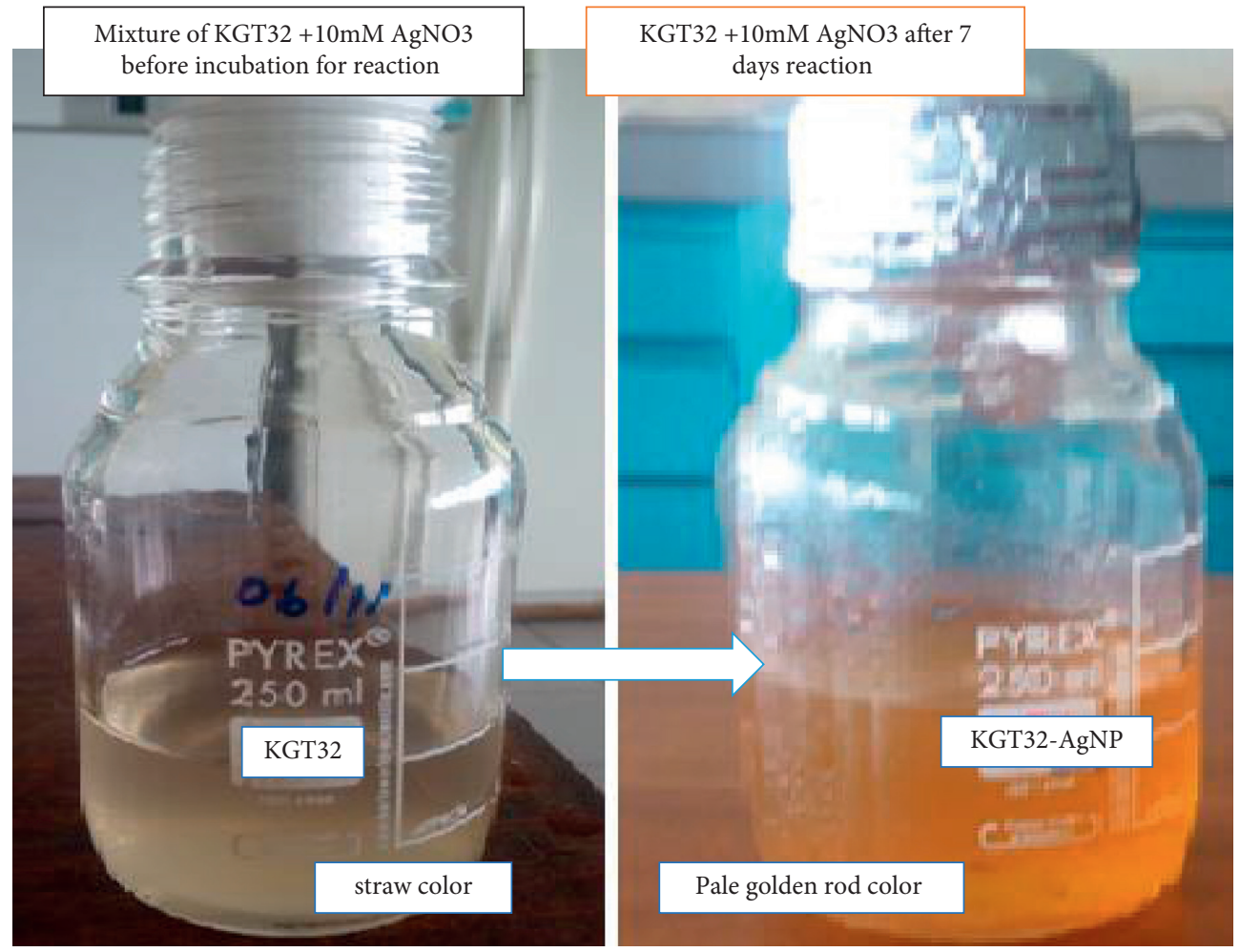

(b)

Figure 1: Color changes after KDT32-AgNPs (a) and KGT32-AgNPs (b) formation.

involvement of functional groups in the formation of KDT32-AgNP. FTIR spectra of KDT32-AgNPs showed a strong and broad band at $3391.31 \mathrm{~cm}^{-1}$ assigned to the stretching vibration of $\mathrm{OH}$. Moreover, the strong and sharp band was also observed at 1640.85 (stretching of-C=C-) and $445.93 \mathrm{~cm}^{-1}$ (stretching of S-S). The shifting of the band 


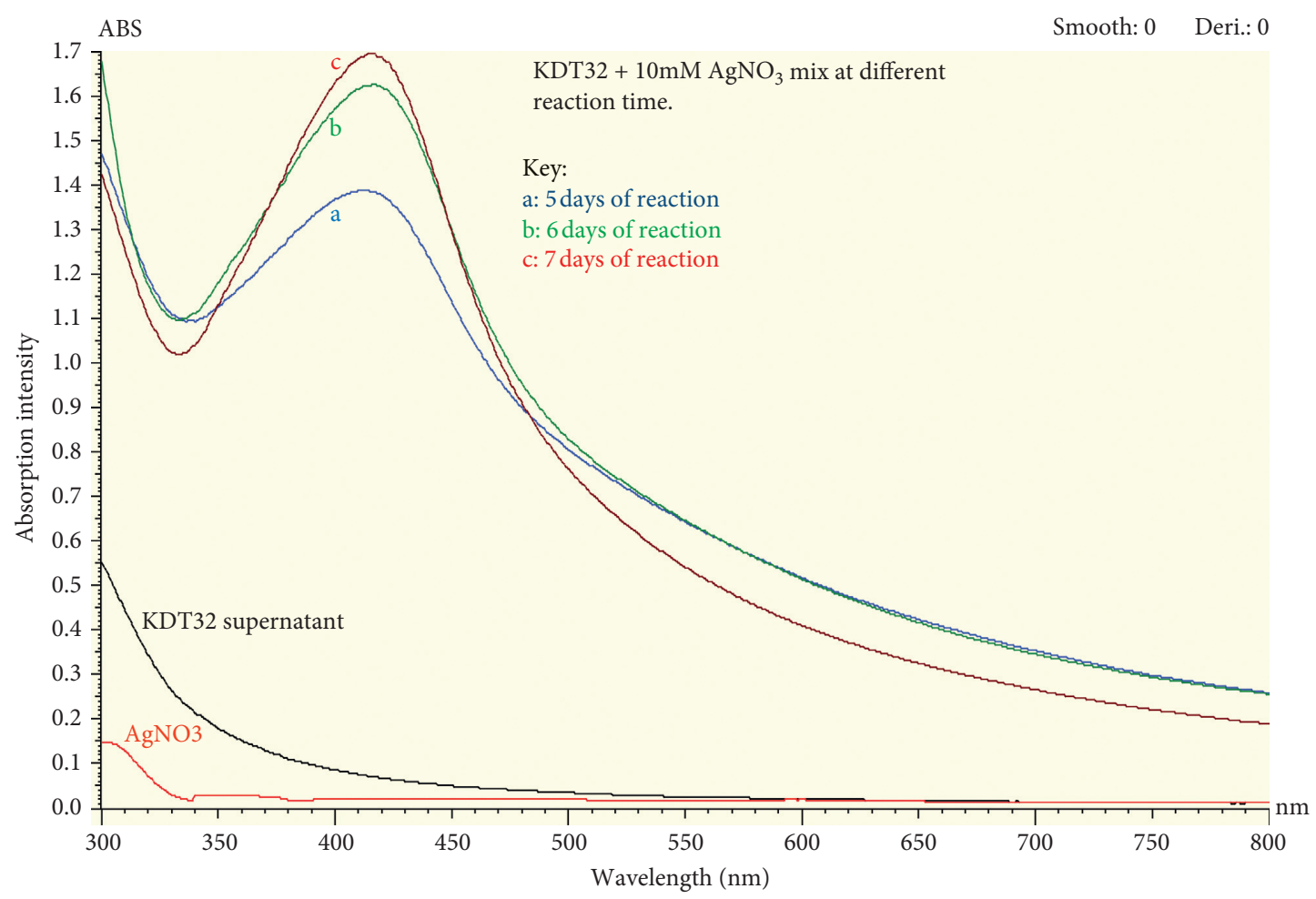

Figure 2: Comparison of the KDT32-AgNPs absorption intensity at maximally centered peak wavelength at different reaction days.

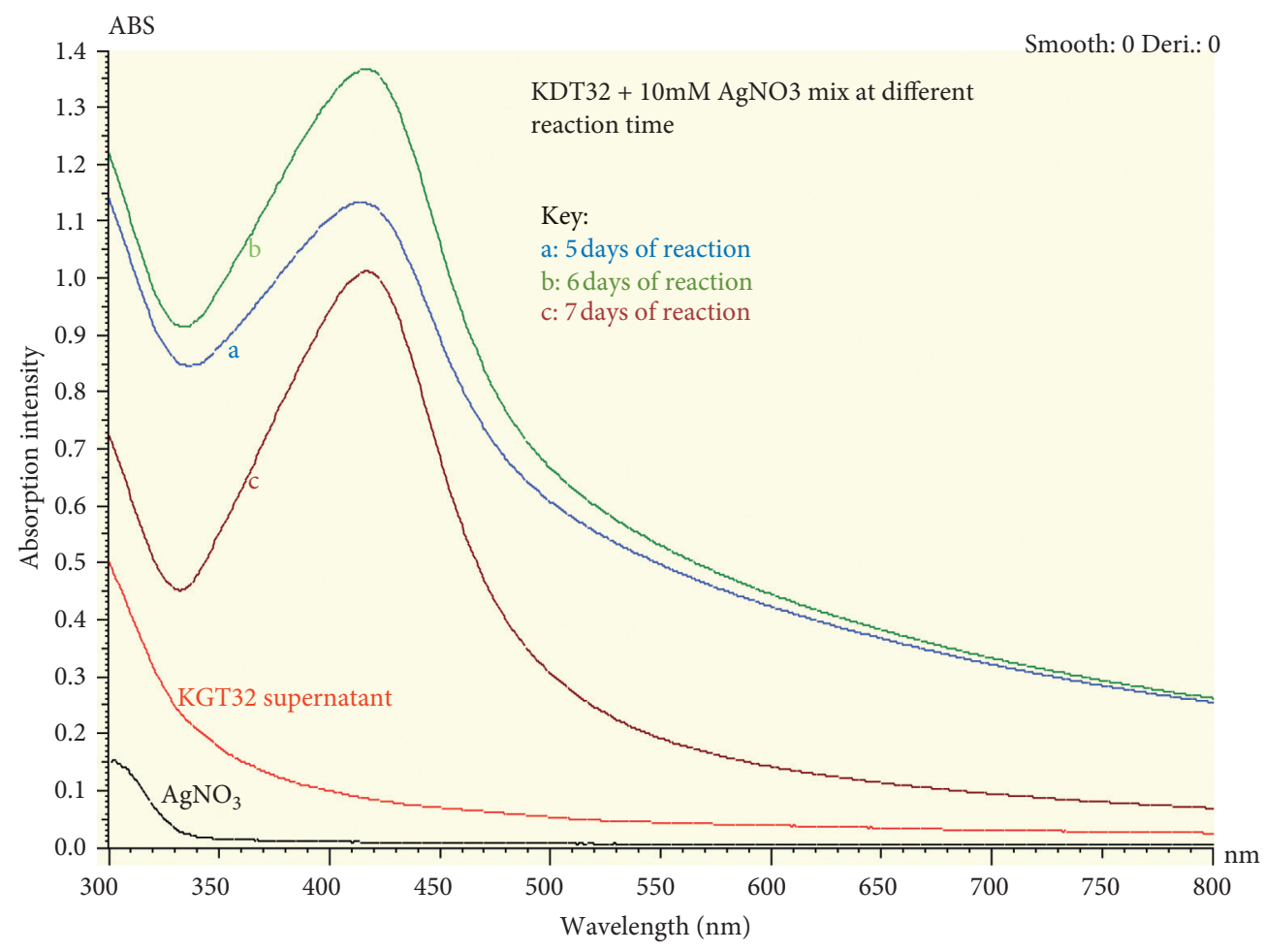

FIGURE 3: Comparison of absorption intensity of KGT32-AgNPs with respect to reaction time.

position from 3386.91 to $3391.31 \mathrm{~cm}^{-1}, 1638.98$ to $1640.85 \mathrm{~cm}^{-1}$, and 461.42 to $445.93 \mathrm{~cm}^{-1}$ may indicate the binding of the biomolecules to the AgNPs (Figure 4). These band shifts indicated that $-\mathrm{OH}, \mathrm{C}=\mathrm{C}$, and $\mathrm{S}-\mathrm{S}$ functional groups from KDT32 metabolite were involved in the synthesis of KDT32-AgNPs.

The FTIR spectra of KGT32 metabolites showed that there were four strong bands (at 3117.76, 2074.04, 1603.98, 


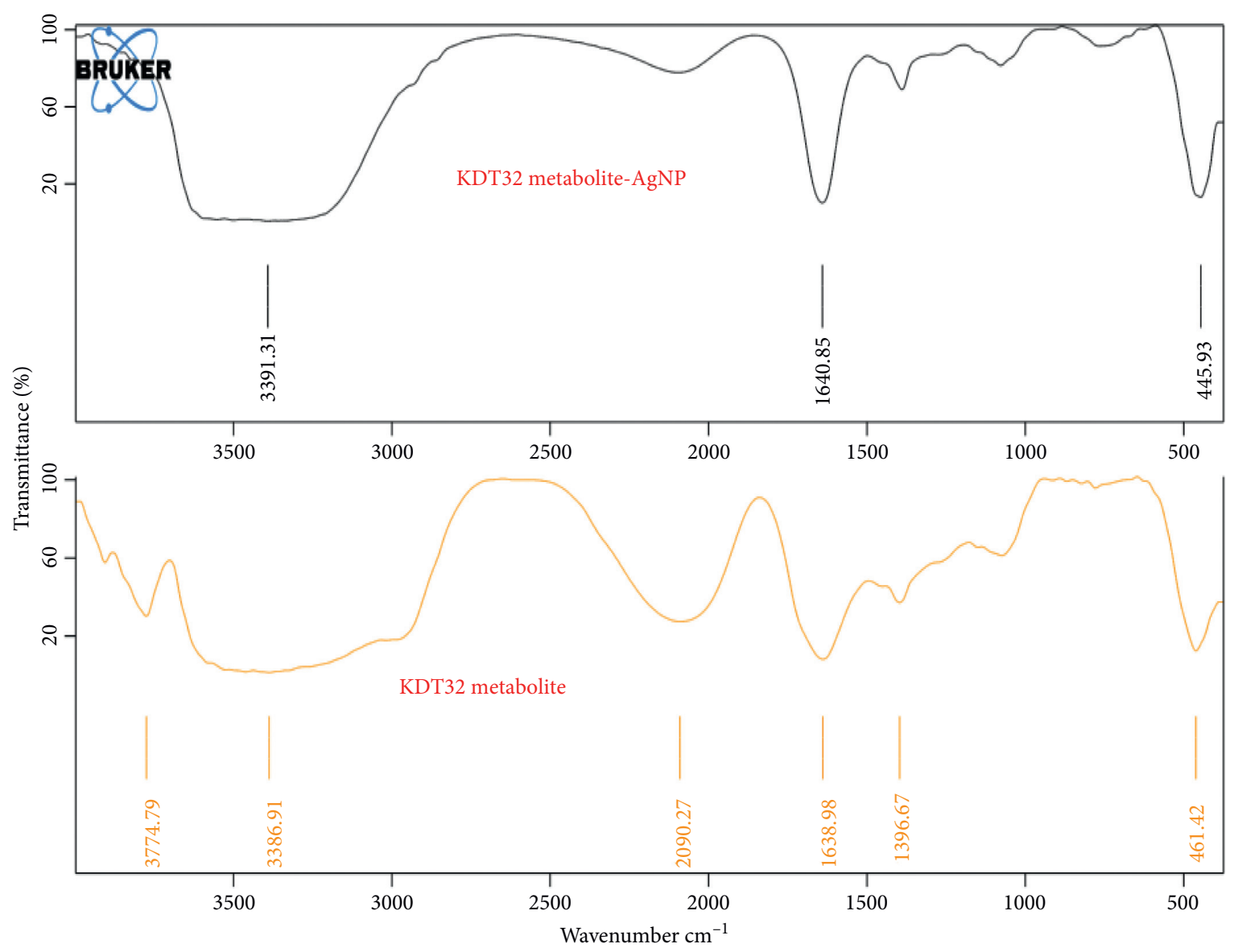

FIGURE 4: FTIR spectra comparison between the KDT32 metabolite and KDT32-AgNPs.

and $743.82 \mathrm{~cm}^{-1}$ ) and one medium band (at $1392.90 \mathrm{~cm}^{-1}$ ) formed (Figure 5). The bands of these wavenumbers are assigned as OH-NCS or (isothiocyanate), C=C, C-H, out plan bending, and S-S, respectively. Moreover, FTIR spectra of KGT32-AgNPs indicated that there were three strong bands observed at $3408.99,1639.15$, and $451.60 \mathrm{~cm}^{-1}$ that showed a shift in band position, shape, and intensity (Figure 5). The shifting band positions from 3117.76 to $3408.99 \mathrm{~cm}^{-1}, 1603.98$ to $1639.15 \mathrm{~cm}^{-1}$, and 743.82 to $451.6 \mathrm{~cm}^{-1}$ indicate that $\mathrm{OH}, \mathrm{C}=\mathrm{C}$, and $\mathrm{C}-\mathrm{H}$ functional groups were involved in the reduction of $\mathrm{Ag}^{+}$and capping of KGT32-AgNPs.

3.1.3. Antibacterial Activity Evaluation of Metabolite-Mediated AgNPs. The inhibition zone of KDT32-AgNP and KGT32-AgNPs as well as their corresponding crude extracts showed antibacterial activity against E. coli and S. typhi (Figure 6).

The inhibition zone of KDT32-AgNPs $(19.0 \pm 1.4 \mathrm{~mm})$ against S. typhi was higher compared to the antibacterial activity of KDT32 crude extracts $(15.0 \pm 0.0 \mathrm{~mm})$ (Table 1). Similarly, KGT32-AgNP $(17.0 \pm 0.0 \mathrm{~mm})$ showed slightly better antibacterial activity against $S$. typhi when compared to the crude extracts of KGT32 $(15.5 \pm 0.7 \mathrm{~mm})$ and $\mathrm{AgNO}_{3}$ $(15.5 \pm 0.7 \mathrm{~nm})$ (Table 1$)$.

\subsection{Identification of Isolates KDT32 and KGT32}

3.2.1. Phenotypic Characterization of Isolates KDT32 and KGT32. The KDT32 and KGT32 colony color was light yellow and white, respectively (Figure 7 and Table 2). The colony shape and texture of both isolates were circular and hard, respectively. Both local isolates were Gram-positive bacteria with filamentous cellular shape and produced catalase enzyme (Figure 7 and Table 2).

The KDT32 and KGT32 isolates grew at a $\mathrm{pH}$ range of 6-12 and 5-12, respectively, and they also grew at $0-7 \%$ and $0-9 \% \mathrm{NaCl}$ concentrations, respectively (Table 2).

3.2.2. Analysis of Amplified $16 S$ rRNA Gene Product. The gel result confirmed that the band of amplified product of KDT32 and KGT32 was between 1000 and 2000 bp size (Figure 8).

3.2.3. Sequence Analysis for Identification of KDT32 and KGT32 Isolates. The GC (Guanine-Cytosine) content for the KDT32 and KGT32 sequence was $58.32 \%$ and $59.6 \%$, respectively (Table 3 ). NCBI-BLASTn similarity search showed that there were multiple hits to members of Streptomyces species for both isolates. The first top hit that showed similarity to the KDT32 sequence was the sequence from Streptomyces sp. MBE174 (AB873097.1) (Figure 9). KDT32 


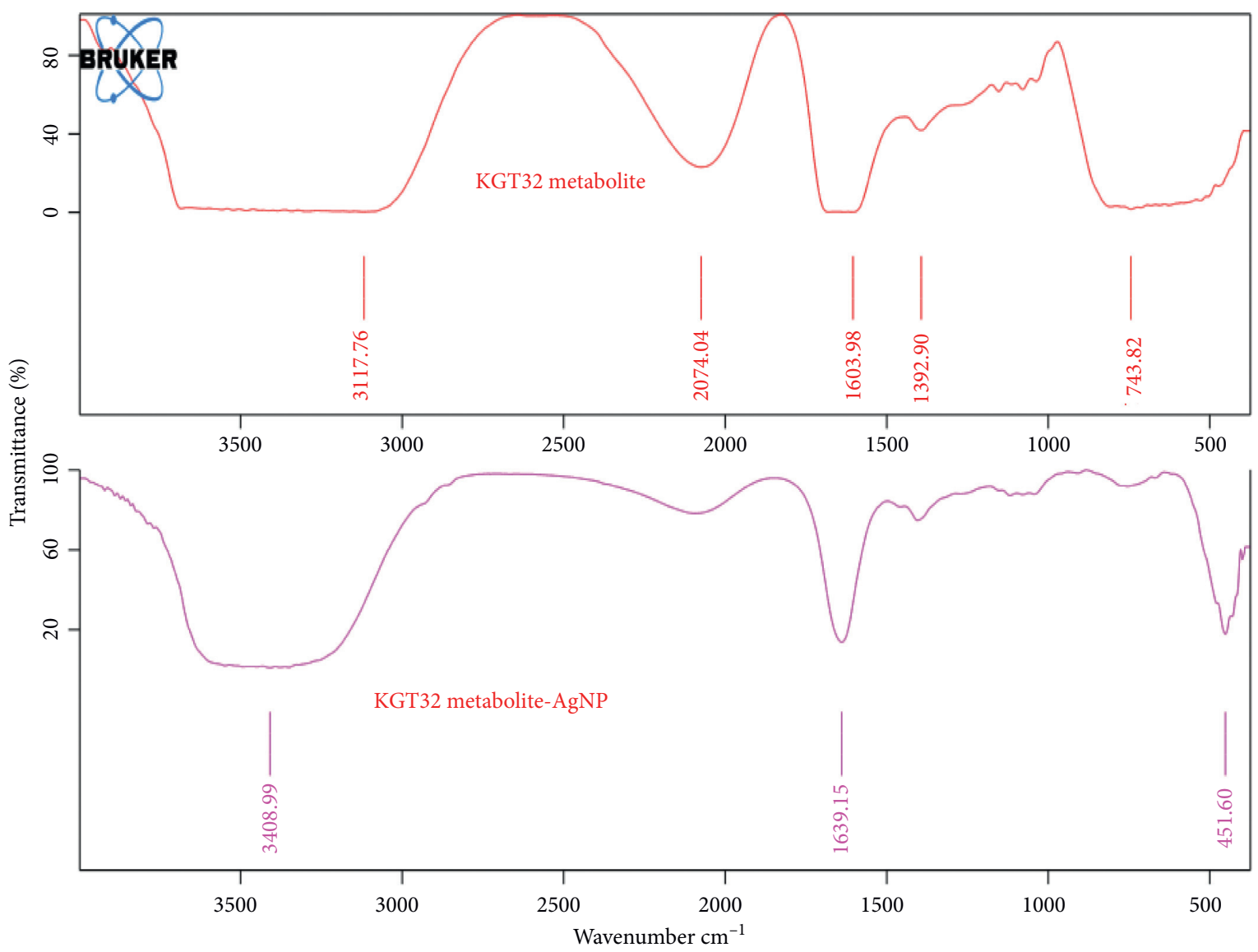

FIGURe 5: Comparison of the FTIR spectra of KGT32 metabolite and KGT32-AgNPs.
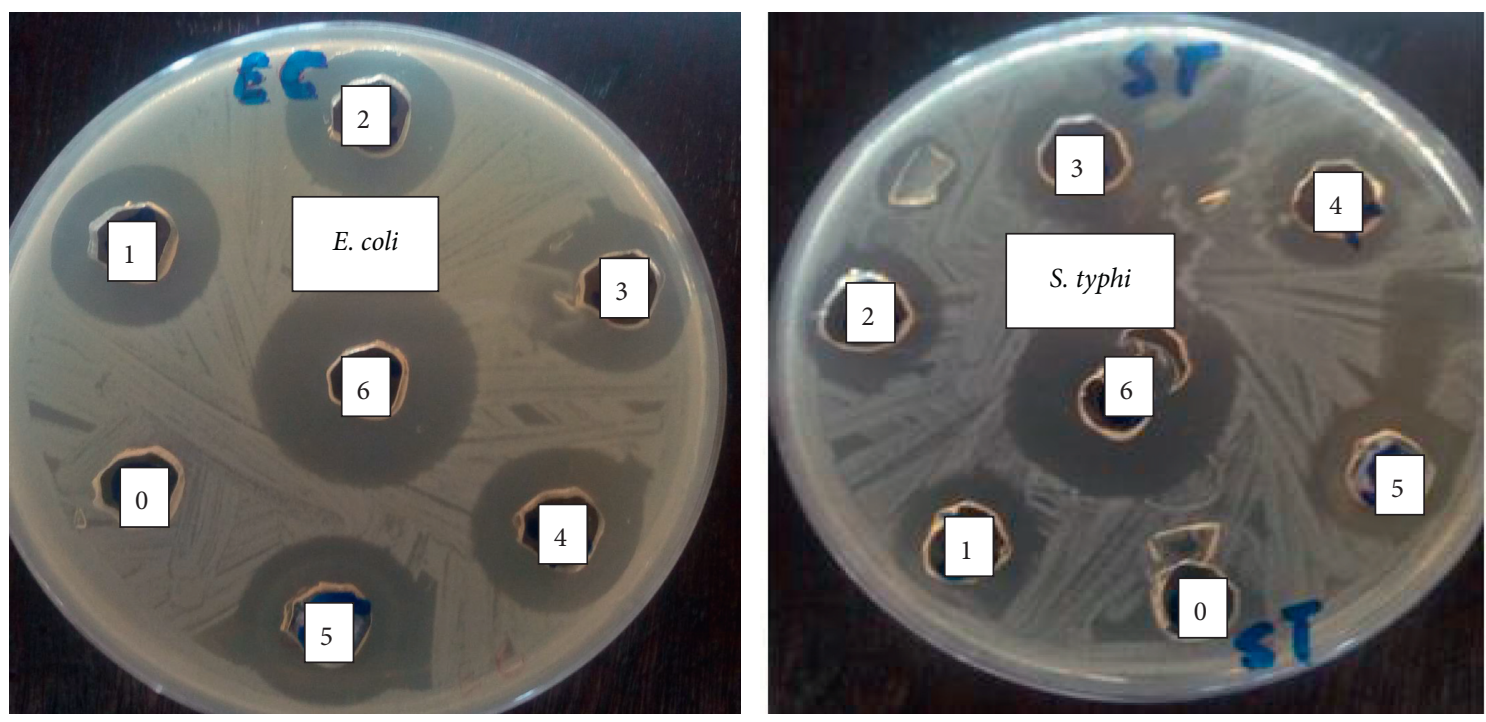

Key: 0 (negative control)

4 (KDT32-AgNP)

1 (KDT32 metabolite)

5 (AgNO3)

2 (KDT32 metabolite)

6 (Streptomycin)

3 (KDT32 metabolite)

FIGURE 6: The bioactivity of silver nanoparticles against E. coli and S. typhi. 
TABLE 1: Evaluation of the antibacterial activity of actinomycete metabolite-mediated AgNPs against selected bacteria pathogens.

\begin{tabular}{lccc}
\hline Bioactivity & & Inhibition zone $(\mathrm{mm})$ against selected bacterial pathogens & S. boydii \\
\hline KDT32 & E. coli & S. typhi & $0 \pm 0.0^{\mathrm{c}}$ \\
KGT32 & $19.0 \pm 1.4^{\mathrm{b}}$ & $15.5 \pm 0.7^{\mathrm{c}}$ & $0 \pm 0.0^{\mathrm{c}}$ \\
KDT32-AgNPs & $20.5 \pm 0.7^{\mathrm{b}}$ & $15.0 \pm 0.0^{\mathrm{c}}$ & $0 \pm 0.0^{\mathrm{c}}$ \\
KGT32-AgNPs $_{\text {AgNO }_{3}}^{22.0 \pm 1.4^{\mathrm{b}}}$ & $19.0 \pm 1.4^{\mathrm{b}}$ & $0 \pm 0.0^{\mathrm{c}}$ \\
STP & $21.5 \pm 0.7^{\mathrm{b}}$ & $17.0 \pm 0.0^{\mathrm{bc}}$ & $11.0 \pm 0.0^{\mathrm{b}}$ \\
Negative control & $20.5 \pm 0.7^{\mathrm{b}}$ & $15.5 \pm 0.7^{\mathrm{c}}$ & $25.5 \pm 0.7^{\mathrm{a}}$ \\
\hline
\end{tabular}

STP (streptomycin or positive control), sterile water (negative control), and 0 (no activity observed). Values are means \pm SD. The values not sharing a common superscript letter $(a>b>c>d)$ in the same column are significantly different at $p<0.05$.
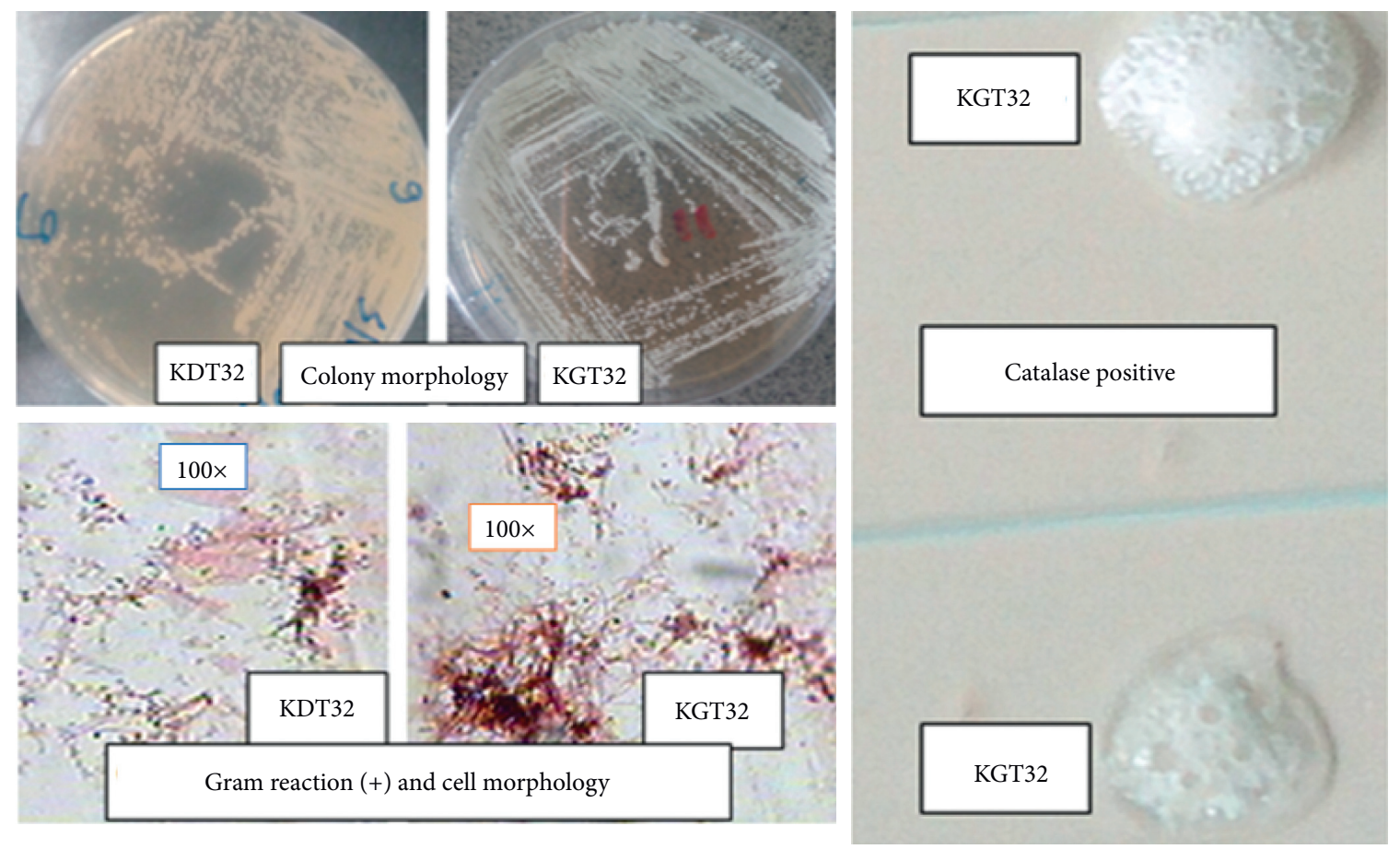

FIGURE 7: The morphology and catalase activity of KDT32 and KGT32 isolates.

TABLE 2: The phenotypic characterization of KDT32 and KGT32 isolates.

\begin{tabular}{|c|c|c|c|}
\hline \multicolumn{2}{|c|}{ Characteristics } & KDT32 & KGT32 \\
\hline \multirow{3}{*}{ Colony } & Color & Light yellow & White \\
\hline & Shape (form) & Circular & Circular \\
\hline & Texture & Hard to scoop & Hard to scoop \\
\hline \multicolumn{2}{|c|}{ Gram reaction } & Positive & Positive \\
\hline \multicolumn{2}{|c|}{ Cell shape } & Filamentous & Filamentous \\
\hline \multicolumn{2}{|c|}{ Catalase test } & Positive & Positive \\
\hline \multicolumn{2}{|c|}{ Growth $\mathrm{pH}$ range } & $6-12$ & $5-12$ \\
\hline \multicolumn{2}{|c|}{ Growth salt range } & $0-7 \%$ & $0-9 \%$ \\
\hline
\end{tabular}

sequence similarity and coverage with Streptomyces sp. MBE174 showed $99 \%$ and $100 \%$, respectively (Table 3). The pairwise alignment result showed that the KDT32 sequence was almost aligned base to base with Streptomyces sp. MBE174 sequence between the subject nucleotide position (coordinate) 417 and 1401 (Figure 10). However, there was a gap observed at 1378 nucleotide position of Streptomyces sp. MBE174 sequence and $T$ nucleotide were seen at nucleotide position 961 of the KDT32 sequence (Figure 10).

Streptomyces sp. strain SP4-AB2 (MH013316.1) was the first top closest species for KGT32 isolates (Figure 11). The KGT32 sequence was aligned with 28-975 nucleotides of Streptomyces sp. strain SP4-AB2 sequence (Figure 12). KGT32 sequence similarity and coverage with Streptomyces sp. strain SP4-AB2 sequence were 99\% (946/948) and $100 \%$, respectively. The statistics of this alignment indicated that there were 946 nucleotides aligned out of 948 (Figure 12). Thus, there were two nucleotide mismatches (2/948) between the two sequences (Table 3 and Figure 12). The first mismatch observed was a $G$ at position 159 of the KGT32 sequence and at position 186 of Streptomyces sp. strain SP4-AB2 sequence, while the second mismatch was at position 866 of the KGT32 sequence and a $G$ at position 893 of Streptomyces sp. strain SP4-AB2 sequence (Figure 12). 


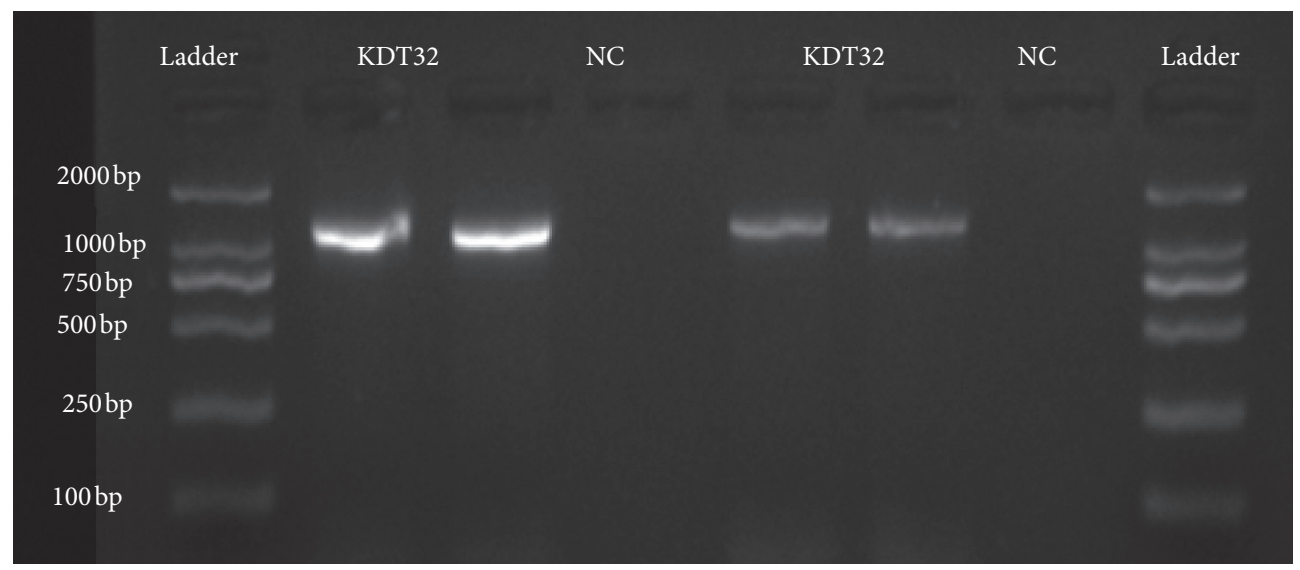

FIGURE 8: The amplified 16S rRNA gene product of KDT32 and KGT 32 isolates using 2\% gel. Ladder: gel pilot mid-range ladder, 100 lanes, six fragments, 100 to $2000 \mathrm{bp}$ (QIAGEN) and NC: negative control (master mix).

TABLE 3: The closest match species from GenBank database with sequences of KDT32 and KGT32 isolates.

\begin{tabular}{|c|c|c|c|c|c|c|c|c|}
\hline Isolate & $\begin{array}{l}\text { Accession } \\
\text { number }\end{array}$ & $\begin{array}{l}\text { Length } \\
(\mathrm{bp})^{*}\end{array}$ & $\begin{array}{c}\mathrm{GC}^{*} \text { content } \\
(\%)\end{array}$ & Closest match & $\begin{array}{l}\text { Accession } \\
\text { number }\end{array}$ & Identity & $\begin{array}{c}\text { Query } \\
\text { coverage } \\
(\%)\end{array}$ & $E$-value \\
\hline KDT32 & МH301089 & 986 & 58.32 & Streptomyces sp. MBE174 & AB873097.1 & $\begin{array}{l}99 \%(985 / \\
986)\end{array}$ & 100 & 0.00 \\
\hline KGT32 & МН301090 & 948 & 59.6 & $\begin{array}{l}\text { Streptomyces sp. strain SP4- } \\
\text { AB2 }\end{array}$ & MH013316.1 & $\begin{array}{c}99 \%(946 / \\
948)\end{array}$ & 100 & 0.00 \\
\hline
\end{tabular}

"Isolate" is the code of our strain isolated from Thika waste damped soil "Length (bp)*" is the total size of the 16S rRNA gene sequence obtained from the isolate; "GC* content" is the ratio of Guanine and cytosine base pairs from the total sequence of our isolate: the star $\left({ }^{*}\right)$ indicates that the results were confirmed from both EzTaxon-e and NCBI-BLASTn databases; "Closest match" is the most similar species from the database to our isolate; "Accession number" is the 16S rRNA gene sequence ID of the most similar species; "Identity" is the similarity of 16S rRNA gene sequence of our isolate and the closet match species sequence; "Query coverage" is the ratio of the sequence from our isolate aligned to the closest species obtained from the database.

\begin{tabular}{|c|c|c|c|c|c|c|}
\hline \multicolumn{7}{|l|}{ Select All None Selecterso. } \\
\hline \multicolumn{7}{|l|}{ 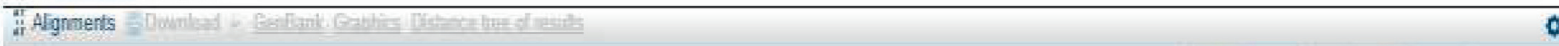 } \\
\hline Descritition & $\begin{array}{l}\text { Max } \\
\text { score }\end{array}$ & $\begin{array}{l}\text { Todal } \\
\text { scure }\end{array}$ & $\begin{array}{l}\text { Ouery } \\
\text { cover }\end{array}$ & $\begin{array}{c}E \\
\text { relue }\end{array}$ & Ident & Aocessisn \\
\hline 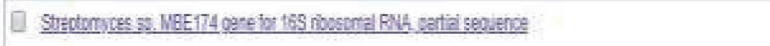 & 1771 & 1771 & $100 \%$ & 0.0 & 994 & ABMTOSII \\
\hline 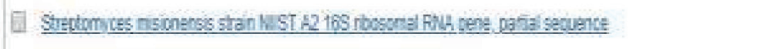 & 1771 & 1771 & $100 \%$ & 0.0 & $99 \%$ & 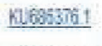 \\
\hline 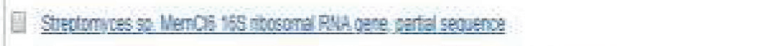 & 1771 & 1771 & wots & 0.0 & $99 \%$ & KFrog:498 1 \\
\hline 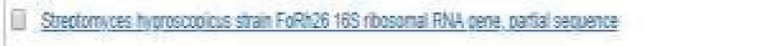 & 1771 & 1771 & $100 \%$ & 0.0 & 996 & na:30043.1 \\
\hline 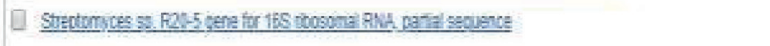 & 1771 & 1771 & $10 \%$ & 0.0 & $99 \%$ & BBA+405T:1 \\
\hline 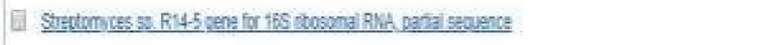 & 1771 & 1771 & $10 \%$ & 0.0 & 998 & $A B E 40421$ \\
\hline 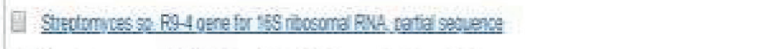 & 1771 & 1771 & 10\%t & 0.0 & $99 \%$ & ABEAmV:1 \\
\hline 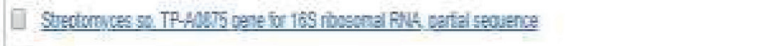 & 1771 & 1771 & $10 \%$ & 0.0 & 99he & AB451554.1. \\
\hline 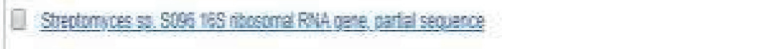 & 1771 & 1771 & $100 \%$ & 0.0 & gges & EFFm421 \\
\hline 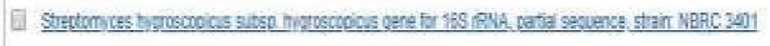 & 1771 & 1771 & $10 \%$ & 0.0 & $94 \%$ & AB18arsa.1 \\
\hline 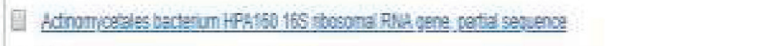 & 1768 & 1768 & $100 \%$ & 0.0 & $99 \%$ & Do14220.1 \\
\hline 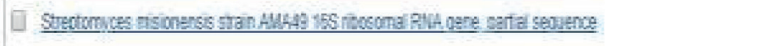 & 1766 & 1766 & $10 \%$ & 0.0 & 996 & LX1299sa \\
\hline 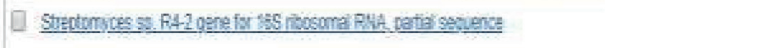 & 1766 & 1766 & $100 \%$ & 0.0 & g9: & BBgand \\
\hline 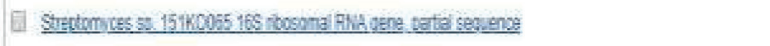 & 1766 & 1766 & $10 \mathrm{~s}$ & 0.0 & $99 \%$ & 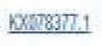 \\
\hline 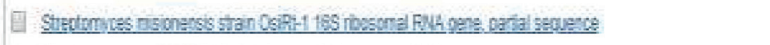 & 1766 & 1766 & whs & 0.0 & $99 \%$ & Kn:3213911 \\
\hline 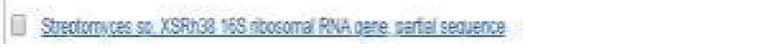 & 1766 & 1766 & $100 \%$ & 0.0 & 996 & KPsonas: \\
\hline
\end{tabular}

Figure 9: NCBI-BLASTn result for KDT32 16S rRNA gene sequence. 


\begin{tabular}{|c|c|c|c|}
\hline dery & 1 & $\begin{array}{l}\text { CTTTCAGCAGGGAAGAAGCGAGAGTGACGGTACCTGCAGAAGAAGCGCCGGCTAACTACG } \\
|||||||||||||||||||||||||||||||||||||||||||||||||||||||||||||||||||||| \mid)\end{array}$ & 0 \\
\hline bjet & 417 & CTTTCAGCAGGGAAGAAGCGAGAGTGACGGTACCTGCAGAAGAAGCGCCGGCTAACTACG & 476 \\
\hline ery & 61 & 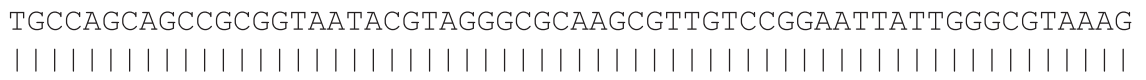 & 120 \\
\hline Sbjet & 477 & TGCCAGCAGCCGCGGTAATACGTAGGGCGCAAGCGTTGTCCGGAATTATTGGGCGTAAAG & 536 \\
\hline Query & 121 & 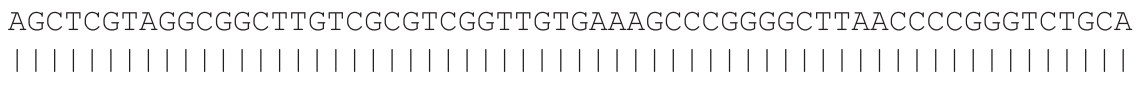 & 80 \\
\hline Sbjet & 537 & AGCTCGTAGGCGGCTTGTCGCGTCGGTTGTGAAAGCCCGGGGCTTAACCCCGGGTCTGCA & 96 \\
\hline uery & 181 & 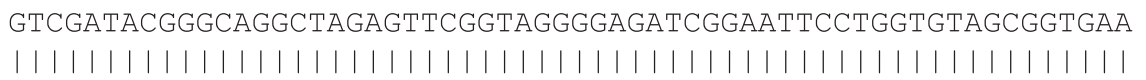 & 40 \\
\hline bjet & 597 & GTCGATACGGGCAGGCTAGAGTTCGGTAGGGGAGATCGGAATTCCTGGTGTAGCGGTGAA & 56 \\
\hline uery & 241 & $\begin{array}{l}\text { ATGCGCAGATATCAGGAGGAACACCGGTGGCGAAGGCGGATCTCTGGGCCGATACTGACG } \\
|||||||||||||||||||||||||||||||||||||||||||||||||||||||||||||||||||||||||||||| \mid ⿰ 亻 丨\end{array}$ & 300 \\
\hline Sbjet & 657 & ATGCGCAGATATCAGGAGGAACACCGGTGGCGAAGGCGGATCTCTGGGCCGATACTGACG & 716 \\
\hline Query & 301 & 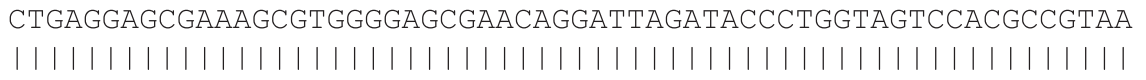 & 360 \\
\hline Sbjet & 717 & CTGAGGAGCGAAAGCGTGGGGAGCGAACAGGATTAGATACCCTGGTAGTCCACGCCGTAA & 776 \\
\hline Query & 361 & 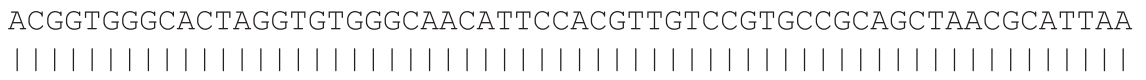 & 420 \\
\hline Sbjet & 777 & AACATTCCACGTTGTCCGTGCCGCAGCTAACC & 836 \\
\hline Query & 421 & 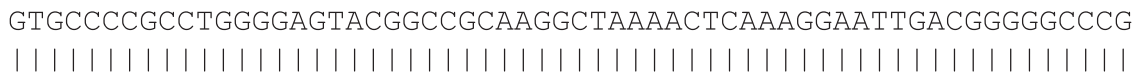 & 480 \\
\hline Sbjet & 837 & GTGCCCCGCCTGGGGAGTACGGCCGCAAGGCTAAAACTCAAAGGAATTGACGGGGGCCCG & 896 \\
\hline Query & 481 & 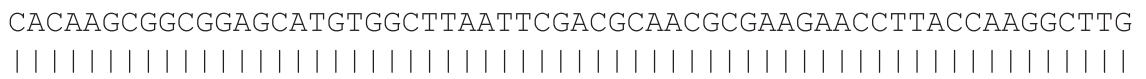 & 540 \\
\hline Sbjet & 897 & CACAAGCGGCGGAGCATGTGGCTTAATTCGACGCAACGCGAAGAACCTTACCAAGGCTTG & 956 \\
\hline Query & 541 & 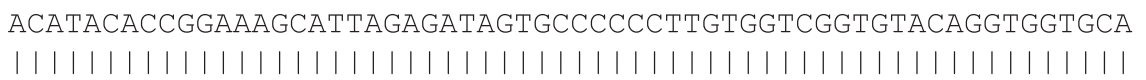 & 600 \\
\hline Sbjet & 957 & ACATACACCGGAAAGCATTAGAGATAGTGCCCCCCTTGTG & 101 \\
\hline Query & 601 & $\begin{array}{l}\text { TGGCTGTCGTCAGCTCGTGTCGTGAGATGTTGGGTTAAGTCCCGCAACGAGCGCAACCCT } \\
|||||||||||||||||||||||||||||||||||||||||||||||||||||||||||||||||||||||||||||||||||l| l\end{array}$ & 660 \\
\hline Sbjet & 1017 & GTICAGCTCGTGTCGTGAGATGTTGGGTTAAGTCCCGCAACGAGCGCAACCCT & to \\
\hline Query & 661 & 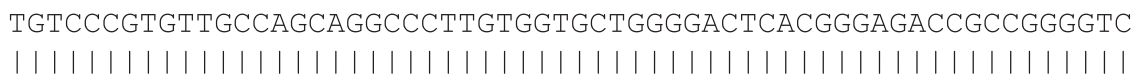 & 720 \\
\hline Sbjet & 1077 & TGTCCCGTGTTGCCAGCAGGCCCTTGTGGTGCTGGGGACTCACGGGAGACCGCCGGGGTC & 36 \\
\hline Query & 721 & 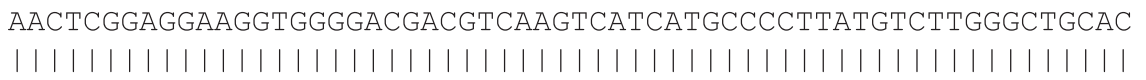 & 780 \\
\hline Sbjet & 1137 & AACTCGGAGGAAGGTGGGGACGACGTCAAGTCATCATGCCCCTTATGTCTTGGGCTGCAC & 1196 \\
\hline Query & 781 & 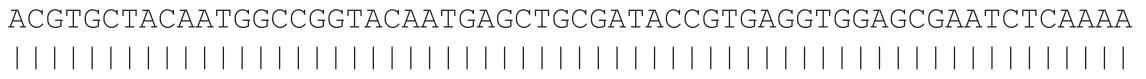 & 840 \\
\hline Sbjet & 1197 & ACGTGCTACAATGGCCGGTACAATGAGCTGCGATACCGTGAGGTGGAGCGAATCTCAAAA & 1256 \\
\hline Query & 841 & 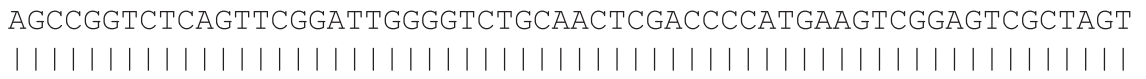 & 900 \\
\hline Sbjet & 1257 & AGCCGGTCTCAGTTCGGATTGGGGTCTGCAACTCGACCCCATGAAGTCGGAGTCGCTAGT & 1316 \\
\hline Query & 901 & 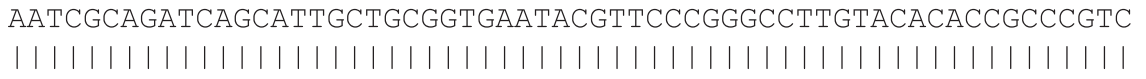 & 960 \\
\hline Sbjet & 1317 & AATCGCAGATCAGCATTGCTGCGGTGAATACGTTCCCGGGCCTTGTACACACCGCCCGTC & ו \\
\hline Query & 961 & $\begin{array}{l}\text { ATCGTCACGAAAGTCGGTAACACCCG } 986 \\
||||||||||||||||||||||||||||\end{array}$ & \\
\hline Sbjet & 377 & A-CGTCACGAAAGTCGGTAACACCCG & \\
\hline
\end{tabular}

Figure 10: The BLAST analysis between the KDT32 (query) sequence and Streptomyces sp. MBE174 (AB873097.1) (sbjct= subject) sequence from the NCBI database. The nucleotide with red color indicates the difference between the query (KDT32) and the subject (Streptomyces sp. MBE174 (AB873097.1)) sequence.

EzTaxon-e server search results confirmed that 30 Streptomyces species showed $99.19 \%-99.8 \%$ sequence similarity to KDT32 isolate (Figure 13). Streptomyces lavenduligriseus strain NRRL ISP-5487 is the first top closest hit that showed $99.8 \%$ sequence similarity to KDT32 sequence (Table 4). In this case, 985/986 bp of the sequence of KDT32 was aligned between 403 and 1388 sequence of S. lavenduligriseus strain NRRL ISP-5487. The number of mismatch nucleotides between the sequence of KDT32 and S. lavenduligriseus strain NRRL ISP-5487 was 2 bps (Table 4). Similarly, 30 Streptomyces species obtained from the EzTaxon-e database that showed $99.26 \%-99.79 \%$ sequence 


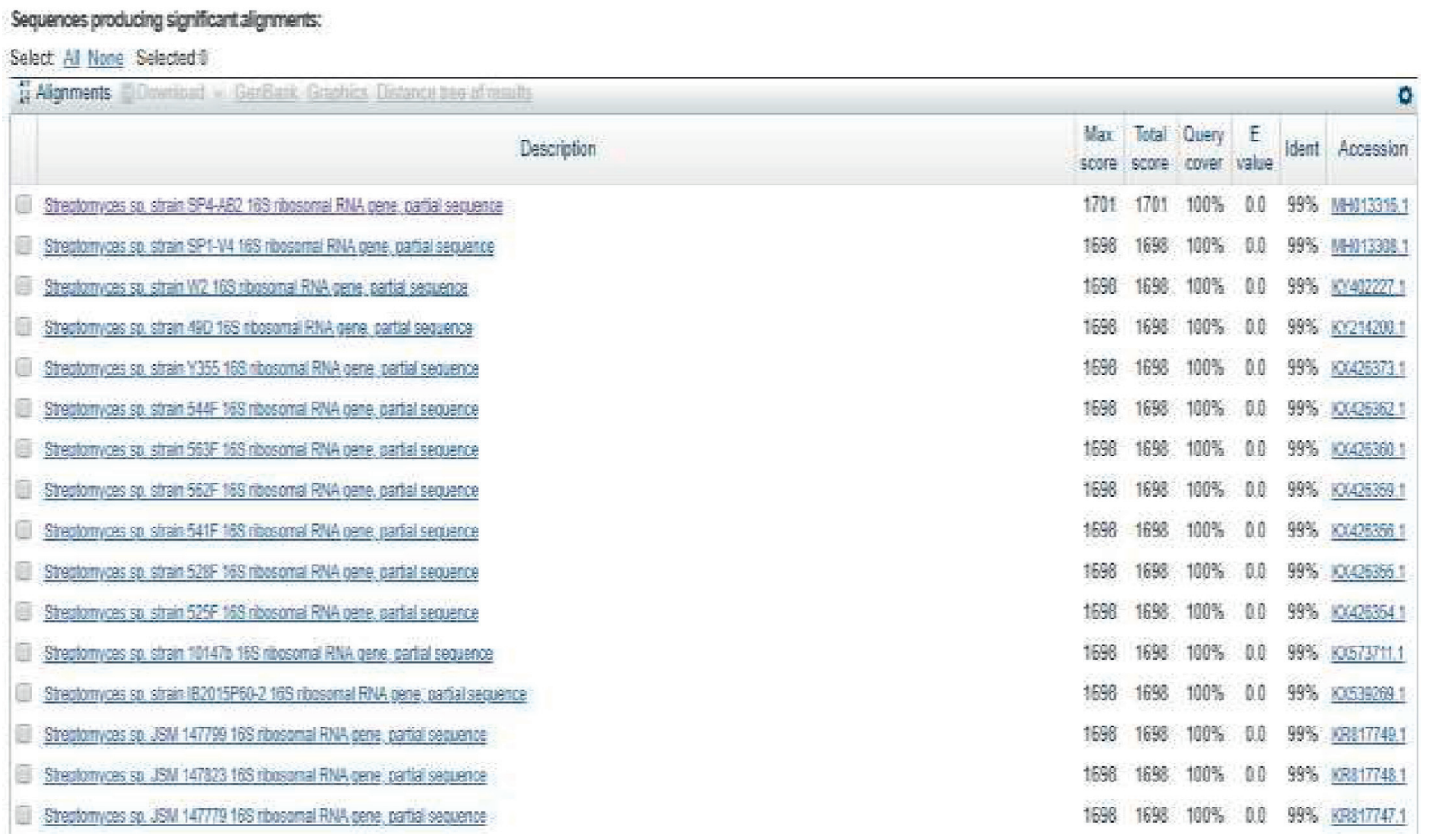

FIgURE 11: NCBI-BLAST result for KGT32 16S rRNA gene sequence.

similarities to KGT32 isolate were retrieved (Figure 9). Four strains showed $99.79 \%$ sequence similarity to the KGT32 sequence. The first most top closest species to the sequence of KGT32 was the sequence of Streptomyces albidoflavus strain DSM40455 (Table 4). From this, 947/948 bp of the sequence of KGT32 was aligned with 264-1211 bp range of sequence of $S$. albidoflavus strain DSM40455. The number of mismatched nucleotides between KGT32 and S. albidoflavus strain DSM40455 was 2/947 (Table 4). Therefore, the isolates KDT32 and KGT32 belonged to Streptomyces species and were deposited in the GenBank database with MH301089 and MH301090 GenBank accession numbers, respectively.

3.2.4. Molecular Phylogenetic Analysis of KDT32 and KGT32 Isolates. The sequence of KDT32 and KGT32 with sequences from 60 Streptomyces type strains retrieved from the EzTaxon-e database was analyzed using NJ and ML algorithms to see the taxonomic position of local isolates (Figure 13). The resulting trees showed that the local isolates were found at different taxonomic positions (Figure 13). It also confirmed that both local isolates showed a clade with different Streptomyces species retrieved from the EzTaxon-e database.

The result of both NJ and ML tree analysis confirmed that the KDT32 isolate formed a monophyletic clade with Streptomyces nodosus strain ATCC 14899 (CP009313; Figure 13). Moreover, the sequence of KDT32 and S. nodosus strain ATCC 14899 showed $99.79 \%$ sequence similarity (Table 4). On the other hand, KGT32 formed a distinct clade with Streptomyces fabae T66 (KM229360) and Streptomyces cinerochromogenes NBRC13822 (AB184507). The KGT32 sequence showed $99.68 \%$ and $99.58 \%$ sequence similarity with S. fabae T66
(KM229360) and S. cinerochromogenes NBRC13822 (AB184507), respectively (Figure 13). Thus, these confirmed that the local isolates that produced bioactive metabolites capable of synthesis of antibacterial silver nanoparticles were grouped under the genus Streptomyces species.

\section{Discussion}

The visual detection of the present study revealed that KDT32 metabolite- $\mathrm{AgNO}_{3}$ and KGT32 metabolite-AgNO reaction solution showed dark salmon and pale golden rod color change, respectively. These may indicate bioreduction of $\mathrm{Ag}^{+}$and morphological indicators to detect the synthesis of AgNPs. The synthesis of AgNPs by cell-free filtrate from Streptomyces rochei MHM13 treated with $\mathrm{AgNO}_{3}$ showed pale yellow color change [17]. In other studies, AgNPs synthesized by metabolite from Streptomyces sp. LK3 [35], S. parvulus SSNP11 [19], Streptomyces sp. NH21 [26], and Streptomyces sp. SS2 [36] showed a dark brown color change. These color changes occur due to the absorption of visible light and the effect of surface plasmon resonance on silver. The differences in color changes may be due to differences in the type of biomolecules involved in bioreduction of $\mathrm{Ag}^{+}$ and capping of AgNPs. These clearly indicate that KDT32 and KGT32 metabolites have the potential to reduce $\mathrm{Ag}^{+}$to form AgNPs.

The absorption intensity result showed that the maximum spectra peak was centered at $415.5 \mathrm{~nm}$ and $416 \mathrm{~nm}$ for KDT32-AgNP and KGT32-AgNPs, respectively. Previous studies revealed that the typical AgNPs show maximum UVvis spectra peaks between 400 and $500 \mathrm{~nm}$, and this is a reliable criterion indicating the formation of AgNPs. Silver 


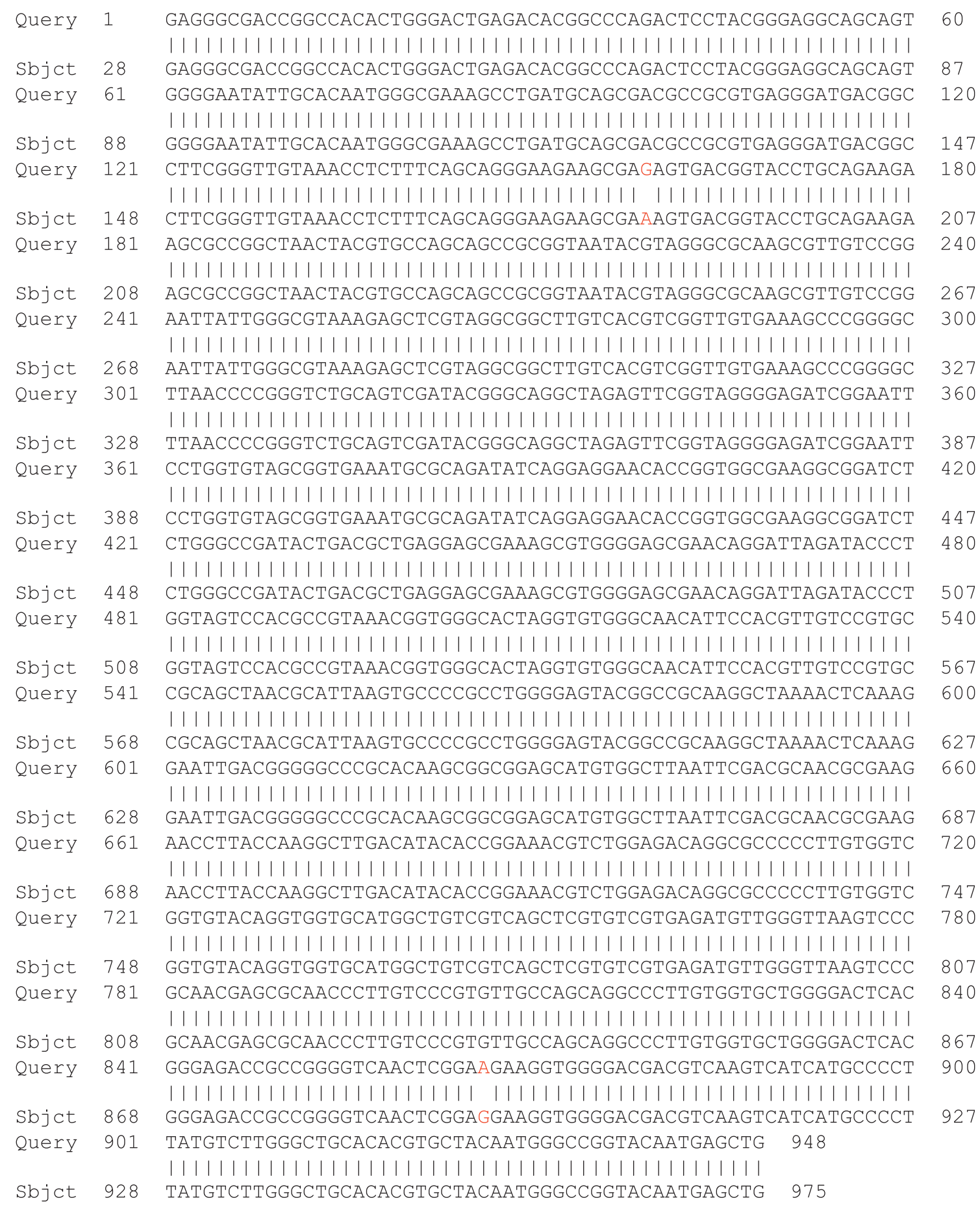

FIGURE 12: The BLAST analysis between the KGT32 (query) sequence and Streptomyces sp. strain SP4-AB2 (sbjct= subject) sequence from the NCBI database. The nucleotide with red color indicates the difference between the query (KGT32) and the subject (Streptomyces sp. strain SP4-AB2) sequence.

nanoparticles synthesized by metabolites from Streptomyces rochei MHM13 showed a characteristic peak at $410 \mathrm{~nm}$ [17]. Silver nanoparticles synthesized by metabolites from Streptomyces sp. SS2 [36] and Streptomyces sp. LK3 [35] showed a characteristic peak at $420 \mathrm{~nm}$. Another study showed that UV-vis spectra of AgNPs synthesized by metabolites from Streptomyces sp. NH21 were observed at 402 and $424 \mathrm{~nm}$ [26].
The functional groups involved in the synthesis of nanoparticles were identified by observing the change in FTIR spectra, band position, shape, and intensity in AgNPs compared to the spectra band of the metabolite only. The band position shift from 3386.91 to $3391.31 \mathrm{~cm}^{-1}, 1638.98$ to $1640.85 \mathrm{~cm}^{-1}$, and 461.42 to $445.93 \mathrm{~cm}^{-1}$ indicates that $\mathrm{O}-\mathrm{H}$ stretch, $\mathrm{C}=\mathrm{C}$, and $\mathrm{S}-\mathrm{S}$ from KDT32 metabolites were major functional groups involved in the synthesis of KDT32- 


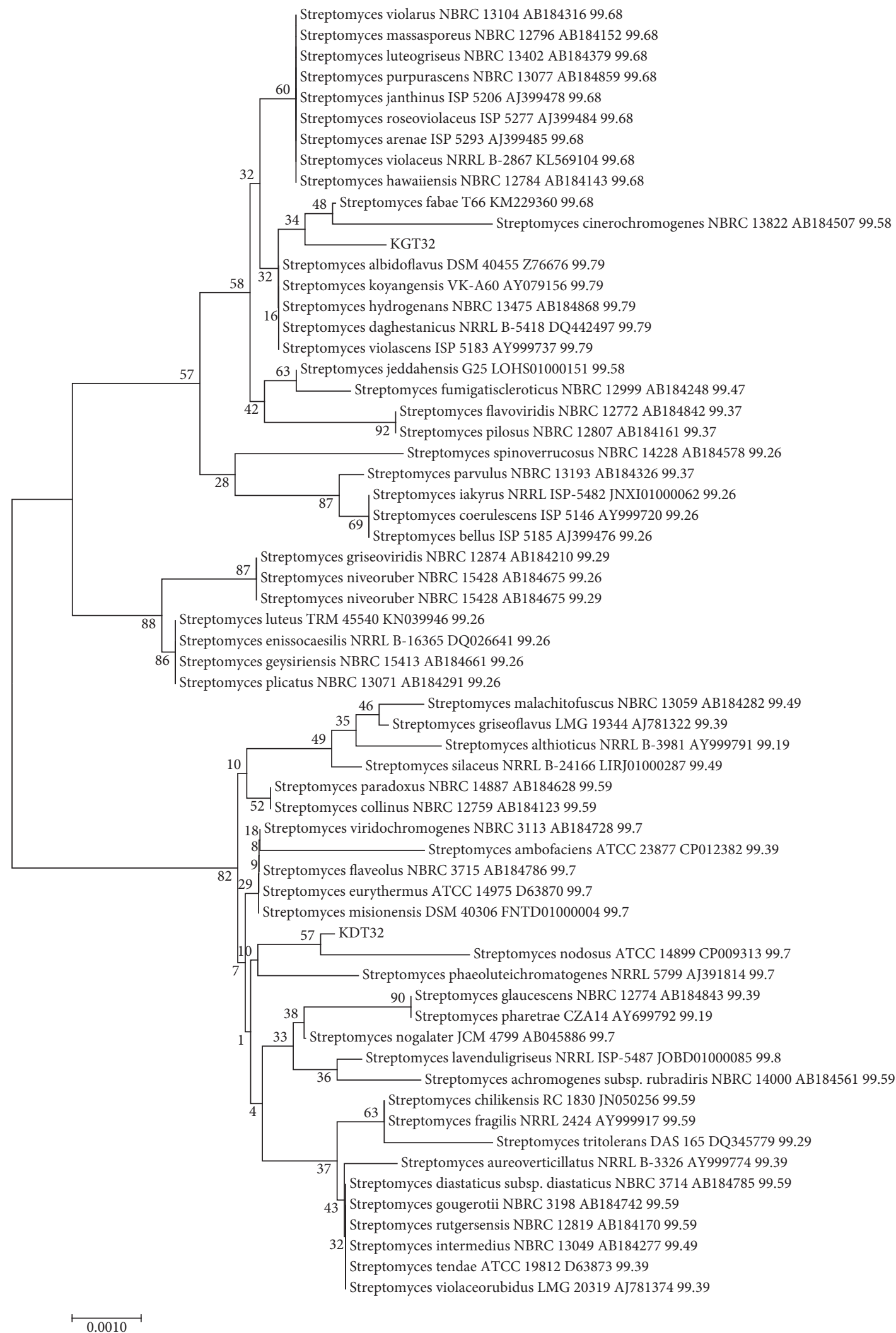

FIGURE 13: Taxonomic position and evolutionary relationship determination of KDT32 and KGT32 isolate sequences with reference sequences (strains of genus Streptomyces) from phylogenetic tree constructed by ML algorithm. The phylogenetic tree was validated by a bootstrap analysis (1000 replications) with values shown at branch nodes. Bar indicates substitutions per nucleotide position. Evolutionary analyses were conducted in MEGA7. Streptomyces violarus NBRC 13104 AB184316 99.68: Streptomyces violarus=taxon name; NBRC $13104=$ strain type; AB184316 = GenBank accession number; $99.68=$ percent of sequence similarity). 
TABLE 4: The KDT32 and KGT32 sequence analysis using EzTaxon databases.

\begin{tabular}{|c|c|c|c|c|c|c|c|}
\hline Isolate & $\begin{array}{c}\text { Completeness } \\
(\%)\end{array}$ & First top hit taxon & $\begin{array}{l}\text { First top hit } \\
\text { strain }^{\mathrm{T}}\end{array}$ & $\begin{array}{l}\text { Accession } \\
\text { number }\end{array}$ & $\begin{array}{l}\text { Similarity } \\
(\%)\end{array}$ & $\begin{array}{c}\text { Diff/ } \\
\text { total } \\
\text { nt }\end{array}$ & Top hit taxonomy \\
\hline KDT32 & 68 & $\begin{array}{c}\text { Streptomyces } \\
\text { lavenduligriseus }\end{array}$ & $\begin{array}{l}\text { NRRL ISP- } \\
\quad 5487^{\mathrm{T}}\end{array}$ & JOBD01000085 & 99.8 & $2 / 985$ & $\begin{array}{c}\text { Bacteria }^{\mathbf{D}} \\
\text { Actinobacteria }^{\mathbf{P}} \\
\text { Actinobacteria }^{\mathbf{C}} \text { Streptomycetales }^{\mathbf{O}} \\
\text { Streptomycetaceae }^{\mathbf{F}} \\
\text { Streptomyces }^{\mathbf{G}}\end{array}$ \\
\hline \multirow{5}{*}{ KGT32 } & \multirow{5}{*}{65.5} & $\begin{array}{l}\text { Streptomyces } \\
\text { albidoflavus }\end{array}$ & $\begin{array}{l}\text { ATCC25422 \& } \\
\text { DSM } 40455^{\mathrm{T}}\end{array}$ & Z76676 & 99.79 & $2 / 847$ & \multirow{5}{*}{$\begin{array}{c}\text { Bacteria }^{\mathbf{D}} \\
\text { Actinobacteria }^{\mathbf{P}} \\
\text { Actinobacteria }^{\mathbf{C}} \\
\text { Streptomycetales }^{\mathbf{O}} \\
\text { Streptomycetaceae }^{\mathbf{F}} \\
\text { Streptomyces }^{\mathbf{G}}\end{array}$} \\
\hline & & $\begin{array}{l}\text { Streptomyces } \\
\text { koyangensis }\end{array}$ & $\mathrm{VK}-\mathrm{A} 60^{\mathrm{T}}$ & AY079156 & 99.79 & $2 / 947$ & \\
\hline & & $\begin{array}{l}\text { Streptomyces } \\
\text { hydrogenans }\end{array}$ & NBRC $13475^{\mathrm{T}}$ & AB184868 & 99.79 & $2 / 947$ & \\
\hline & & $\begin{array}{l}\text { Streptomyces } \\
\text { daghestanicus }\end{array}$ & NRRL B-5418 & DQ442497 & 99.79 & $2 / 946$ & \\
\hline & & $\begin{array}{l}\text { Streptomyces } \\
\text { violascens }\end{array}$ & ISP $5183^{\mathrm{T}}$ & AY999737 & 99.79 & $2 / 945$ & \\
\hline
\end{tabular}

"Completeness" is the ratio of the length of our sequence to the full-length sequence; "Top hit taxon" is the first closet species in the database; "First top hit

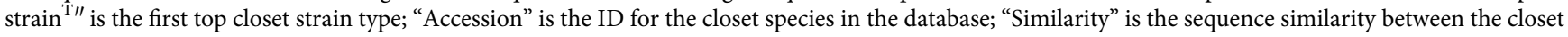
species and our isolate; "Different/total nucleotide" is the number of mismatched base pair between the closet species and our isolate from the total number of compared sequences; "Top hit taxonomy" is the taxonomical hierarchy of our isolate-based 16S rRNA gene sequence from Domain (Bacteria) to genus (Streptomyces $)\{\mathrm{D}=$ domain, $\mathrm{P}=$ phylum, $\mathrm{C}=$ class, $\mathrm{O}=$ order, $\mathrm{F}=$ family, $\mathrm{G}=$ genus $\}$

AgNPs. Similarly, the shift in band position from 3117.76 to $3408.99 \mathrm{~cm}^{-1}, 1603.98$ to $1639.15 \mathrm{~cm}^{-1}$, and 743.82 to $451.6 \mathrm{~cm}^{-1}$ reveals that $\mathrm{O}-\mathrm{H}, \mathrm{C}=\mathrm{C}$, and $\mathrm{C}-\mathrm{H}$ biomolecules from KGT32 metabolites were involved in the synthesis of KGT32-AgNPs. This band peak shift alteration between the metabolite and the metabolite mediated by AgNPs shows the existence of biomolecules that were involved in the reduction of $\mathrm{Ag}^{+}$and capping of AgNPs. As reported, antibacterial compounds have active functional groups such as amide and hydroxyl groups to reduce $\mathrm{Ag}^{+}$and cap AgNPs [18]. Another study showed that the active functional group $\mathrm{O}-\mathrm{H}$ $\left(3417 \mathrm{~cm}^{-1}\right)$ [35] was involved in the reduction of $\mathrm{Ag}^{+}$and capping of antibacterial AgNPs. Similarly, earlier studies have reported that $-\mathrm{OH}\left(3384 \mathrm{~cm}^{-1}\right)$ is one of the functional groups used to reduce $\mathrm{Ag}^{+}$and capping of AgNPs [37]. These clearly indicate that KDT32 and KGT32 isolates are the source of metabolites having potential functional groups that reduce $\mathrm{Ag}^{+}$and capping AgNPs.

The bioassay study of KDT32-AgNP and KGT32-AgNP showed antibacterial activity against E. coli and S. typhi. The inhibition zone of KDT32-AgNP against E. coli and S. typhi was $22.0 \pm 1.4 \mathrm{~mm}$ and $19.0 \pm 1.4 \mathrm{~mm}$, respectively. Similarly, KGT32-AgNP revealed an inhibition zone of $21.5 \pm 0.7 \mathrm{~mm}$ and $17.0 \pm 0.0 \mathrm{~mm}$ against $E$. coli and $S$. typhi, respectively. However, the present study showed that no antibacterial activity was observed against $S$. boydii and a similar result was reported by Chauhan et al. [18]. Earlier reports showed that AgNP synthesized by Streptomyces rochei MHM13 metabolite showed $16 \mathrm{~mm}$ and $18 \mathrm{~mm}$ inhibition zone against $E$. coli and S. typhi, respectively [17]. In another study [36], AgNP synthesized by metabolites from Streptomyces sp. SS2 showed $18.25 \pm 1.5 \mathrm{~mm}$ inhibition zone against E. coli. Silver nanoparticles synthesized by $S$. parvulus SSNP11 metabolites showed a $26 \mathrm{~mm}$ inhibition zone against S. typhi [19]. These clearly indicate that KDT32 and KGT32 metabolite mediated the synthesis of antibacterial AgNPs with potential bionanotechnology that can be used in biomedical applications.

The present study demonstrated that both KDT32 and KGT32 isolates were Gram positive, had filamentous cell shape, and produced catalase enzyme that grew at 6-12 and $5-12 \mathrm{pH}$ values and $0-7 \%$ and $0-9 \% \mathrm{NaCl}$ concentrations, respectively. This is in agreement with studies that antibacterial metabolites producing Streptomyces species isolated from soil showed growth between 4 and $12 \mathrm{pH}$ and $0-7 \%$ salt concentration $[38,39]$.

NCBI-BLASTn search results indicate that sequence of KDT32 isolate showed $99 \%$ sequence similarity with a sequence of Streptomyces sp. MBE174. The biomedical and pharmaceutical application of Streptomyces sp. MBE174 is unknown. Moreover, based on the EzTaxon-e database search result, the sequence of KDT32 isolate showed $99.8 \%$ sequence similarity with $S$. lavenduligriseus strain NRRL ISP-5487 that produced polyene macrolides (pentenomycine II, pentenomycine III, and narangomycine) [40].

Similarly, the sequences of KGT32 isolate showed $99 \%$ similarity with Streptomyces sp. strain SP4-AB2 (MH013316.1) with both medical and industrial roles but yet to be determined. EzTaxon-e similarity search indicated that sequence of KGT32 isolate showed $99.79 \%$ similarity with S. albidoflavus strain DSM40455, S. koyangensis strain VK-A60, S. hydrogenans strain NBRC 13475, S. daghestanicus strain NRRL B-5418, and S. violascens strain ISP 5183. These microbes are known in the production of different antimicrobial compounds such as paulomycin A and paulomycin B [41], 4-phenyl-3-butenoic acid [42], actinomycin D [43], and valinomycin [44], respectively. Unlike local isolates KDT32 and KGT32, a literature search about the role of these reference 
Streptomyces species in nanodrug synthesis has not been reported.

The phylogenetic tree constructed from KDT32, KGT32, and reference sequences retrieved from the EzTaxon-e database revealed that the taxonomic position of both KDT32 and KGT32 isolates formed different clades with members of genus Streptomyces. Both NJ and ML trees inferred that the KDT32 isolate formed a monophyletic clade with S. nodosus strain ATCC 14899 that had $99.7 \%$ sequence similarity. Streptomyces nodosus is known in the production of antifungal antibiotics (polyene macrolide antibiotic, amphotericin B) [45] and other bioactive compounds (polyketides, peptides, siderophores, and terpenes) [46]. On the other hand, the KGT32 isolate formed a distinct clade with $S$. fabae strain T66 and S. cinerochromogenes strain NBRC13822. Streptomyces fabae is known for the production of antibacterial and antifungal antibiotics [47] and $S$. cinerochromogenes produced cineromycin B that has a role in antiadipocyte differentiation [48]. However, the role of these reference Streptomyces species in nanodrug synthesis is unknown. Thus, not only do KDT32 and KGT32 isolates produce antibacterial metabolites but also the metabolites are capable of synthesizing antibacterial AgNPs.

\section{Conclusion}

Bioactive metabolites from KDT32 and KGT32 isolates synthesize antibacterial AgNP (KDT32-AgNP and KGT32AgNP) against E. coli and S. typhi but not against S. boydii. Due to its bactericidal activity of the synthesized AgNPs, hence, KDT32 and KGT32 metabolites can be used for antibacterial activity in different biomedical applications. The KDT32 and KGT32 isolates that produce bioactive metabolites to synthesize antibacterial AgNPs were identified as Streptomyces species.

\section{Data Availability}

The data used to support the findings of this study are included within the article.

\section{Conflicts of Interest}

The authors declare no conflicts of interest.

\section{Acknowledgments}

This research work was funded by the African Union Commission (ADF/BD/WP/2013/68 to CNM) and Japanese International Co-operation Agency (JICA) (00025 to CNM), and the authors also thank the institutes. The authors are also grateful to PAUISTI Molecular and Biotechnology lab, KIRDI, KEMRI, and JKUAT chemistry lab staff for allowing the lab facilities to be used for this research work. The first author also acknowledges Gondar University that gave him supportive material used for this study.

\section{References}

[1] J. M. A. Blair, M. A. Webber, A. J. Baylay, D. O. Ogbolu, and L. J. V. Piddock, "Molecular mechanisms of antibiotic resistance," Nature Reviews Microbiology, vol. 13, no. 1, pp. 42-51, 2014.

[2] K. S. Kaye and J. M. Pogue, "Infections caused by resistant gram-negative bacteria: epidemiology and management," Pharmacotherapy: The Journal of Human Pharmacology and Drug Therapy, vol. 35, no. 10, pp. 949-962, 2015.

[3] C. G. Giske, D. L. Monnet, O. Cars, and Y. Carmeli, "Clinical and economic impact of common multidrug-resistant gramnegative bacilli," Antimicrobial Agents and Chemotherapy, vol. 52, no. 3, pp. 813-821, 2008.

[4] N. Sabtu, D. A. Enoch, and N. M. Brown, "Antibiotic resistance: what, why, where, when and how?" British Medical Bulletin, vol. 116, no. 1, pp. 105-113, 2015.

[5] S. Omulo, S. M. Thumbi, M. K. Njenga, and D. R. Call, "A review of 40 years of enteric antimicrobial resistance research in Eastern Africa: what can be done better?.: What can be done better?" Antimicrobial Resistance and Infection Control, vol. 4, no. 1, pp. 1-13, 2015.

[6] M. E. Ibrahim, N. E. Bilal, and M. E. Hamid, "Increased multidrug resistant Escherichia coli from hospitals in Khartoum state, Sudan," African Health Sciences, vol. 12, no. 3, pp. $368-375,2012$.

[7] D. Lin, K. Chen, E. Wai-Chi Chan, and S. Chen, "Increasing prevalence of ciprofloxacin-resistant food-borne Salmonella strains harboring multiple PMQR elements but not target gene mutations," Scientific Reports, vol. 5, no. 1, pp. 1-8, 2015.

[8] F. Jafari, M. Hamidian, M. Rezadehbashi et al., "Prevalence and antimicrobial resistance of diarrheagenic Escherichia coli and Shigella species associated with acute diarrhea in Tehran, Iran," Journal of Infectious Disease and Medical Microbiololgy, vol. 20, no. 3, pp. e56-e62, 2009.

[9] S. Prabhu and E. K. Poulose, "Silver nanoparticles: mechanism of antimicrobial action, synthesis, medical applications, and toxicity effects," International Nano Letters, vol. 2, no. 32, pp. 1-10, 2012.

[10] R. S. Prakasham, B. S. Kumar, Y. S. Kumar, and G. G. Shankar, "Characterization of silver nanoparticles synthesized by using marine isolate Streptomyces albidoflavus," Journal of Microbiology and Biotechnology, vol. 22, no. 5, pp. 614-621, 2012.

[11] S. Wagi and A. Ahmed, "Bacterial nanobiotic potential," Green Processing and Synthesis, vol. 9, no. 1, pp. 203-211, 2020.

[12] A. Bakhtiari-Sardari, M. Mashreghi, H. Eshghi, F. BehnamRasouli, E. Lashani, and B. Shahnavaz, "Comparative evaluation of silver nanoparticles biosynthesis by two cold-tolerant Streptomyces strains and their biological activities," Biotechnology Letters, vol. 42, no. 10, pp. 1985-1999, 2020.

[13] A. A. Hamed, H. Kabary, M. Khedr, and A. N. Emam, "Antibiofilm, antimicrobial and cytotoxic activity of extracellular green-synthesized silver nanoparticles by two marinederived actinomycete," RSC Advances, vol. 10, no. 17, pp. 10361-10367, 2020.

[14] C. Barros, S. Fulaz, D. Stanisic, and L. Tasic, "Biogenic nanosilver against multidrug-resistant bacteria (MDRB)," Antibiotics, vol. 7, no. 3, pp. 69-24, 2018.

[15] P. Golinska, M. Wypij, A. P. Ingle, I. Gupta, H. Dahm, and M. Rai, "Biogenic synthesis of metal nanoparticles from actinomycetes: biomedical applications and cytotoxicity," Applied Microbiology and Biotechnology, vol. 98, no. 19, pp. 8083-8097, 2014. 
[16] P. Manivasagan, J. Venkatesan, K. Sivakumar, and S.-K. Kim, "Actinobacteria mediated synthesis of nanoparticles and their biological properties: a review," Critical Reviews in Microbiology, vol. 42, no. 2, pp. 1-13, 2016.

[17] H. M. Abd-Elnaby, G. M. Abo-Elala, U. M. Abdel-Raouf, and M. M. Hamed, "Antibacterial and anticancer activity of extracellular synthesized silver nanoparticles from marine Streptomyces rochei MHM13," The Egyptian Journal of Aquatic Research, vol. 42, no. 3, pp. 301-312, 2016.

[18] R. Chauhan, A. Kumar, and J. Abraham, "A biological approach to synthesis of silver nanoparticles with Streptomyces sp JAR1 and its antimicrobial activity," Scientia Pharmaceutica, vol. 81, no. 2, pp. 607-621, 2013.

[19] R. S. Prakasham, B. S. Kumar, Y. S. Kumar, and K. P. Kumar, "Production and characterization of protein encapsulated silver nanoparticles by marine isolate Streptomyces parvulus SSNP11," Indian Journal of Microbiology, vol. 54, no. 3, pp. 329-336, 2014.

[20] M. Wypij, J. Czarnecka, M. Świecimska, H. Dahm, M. Rai, and P. Golinska, "Synthesis, characterization and evaluation of antimicrobial and cytotoxic activities of biogenic silver nanoparticles synthesized from Streptomyces xinghaiensis OF1 strain," World Journal of Microbiology and Biotechnology, vol. 34, no. 2, pp. 1-13, 2018.

[21] A. Muleta and F. Assefa, "Isolation and screening of antibiotic producing actinomycetes from the rhizosphere and agricultural soils," African Journal of Biotechnology, vol. 17, pp. 700-714, 2018.

[22] A. Bizuye, C. Bii, C. Bii, G. Erastus, and N. Maina, "Antibacterial metabolite prospecting from Actinomycetes isolated from waste damped soils from Thika, central part of Kenya," Asian Pacific Journal of Tropical Disease, vol. 7, no. 12, pp. 757-764, 2017.

[23] A. Bizuye, F. Moges, and B. Andualem, "Isolation and screening of antibiotic producing actinomycetes from soils in Gondar town, North West Ethiopia," Asian Pacific Journal of Tropical Disease, vol. 3, no. 5, pp. 375-381, 2013.

[24] M. Kibret, J. F. Guerrero-Garzón, E. Urban et al., "Streptomyces spp from Ethiopia producing antimicrobial compounds: characterization via bioassays, genome analyses, and mass spectrometry," Frontiers in Microbiology, vol. 9, pp. 1-13, 2018.

[25] M. C. Rotich, E. Magiri, C. Bii, and N. Maina, "Bio-Prospecting for broad spectrum antibiotic producing actinomycetes isolated from virgin soils in kericho county, Kenya," Advances in Microbiology, vol. 07, no. 1, pp. 56-70, 2017.

[26] M. Składanowski, M. Wypij, D. Laskowski, P. Golińska, H. Dahm, and M. Rai, "Silver and gold nanoparticles synthesized from Streptomyces sp. isolated from acid forest soil with special reference to its antibacterial activity against pathogens," Journal of Cluster Science, vol. 28, no. 1, pp. 59-79, 2017.

[27] P. S. Kumar, C. Balachandran, V. Duraipandiyan, D. Ramasamy, S. Ignacimuthu, and N. A. Al-dhabi, "Extracellular biosynthesis of silver nanoparticle using Streptomyces sp. 09 PBT 005 and its antibacterial and cytotoxic properties," Applied Nanoscience, vol. 5, pp. 169-180, 2015.

[28] R. A. Ataee, A. Mehrabi-Tavana, S. M. J. Hosseini, K. Moridi, and M. G. Zadegan, "A method for antibiotic susceptibility testing: applicable and accurate," Jundishapur Journal of Microbiology, vol. 5, no. 1, pp. 341-345, 2012.

[29] Q. Li, X. Chen, Y. Jiang, and C. Jiang, "Morphological identification of actinobacteria," in Actinobacteria-Basics and
Biotechnological Applications, D. Dhanasekaran and Y. Jiang, Eds., pp. 60-86, IntechOpen, London, UK, 2016.

[30] S. Bowman, P. Roffey, D. McNevin, and M. E. Gahan, "Evaluation of commercial DNA extraction methods for biosecurity applications," Australian Journal of Forensic Sciences, vol. 48, no. 4, pp. 407-420, 2016.

[31] P. Monciardini, M. Sosio, L. Cavaletti, C. Chiocchini, and S. Donadio, "New PCR primers for the selective amplification of 16S rDNA from different groups of actinomycetes1," FEMS Microbiology Ecology, vol. 42, no. 3, pp. 419-429, 2002.

[32] X. Chen, Y. Jiang, Q. Li, L. Han, and C. Jiang, "Molecular phylogenetic identification of actinobacteria xiu," Actinobacteria-Basics and Biotechnological Applications, vol. 56, pp. 141-174, 2017.

[33] D. A. Benson, I. Karsch-Mizrachi, K. Clark, D. J. Lipman, J. Ostell, and E. W. Sayers, "GenBank," Nucleic Acids Research, vol. 40, no. D1, pp. D48-D53, 2012.

[34] S.-H. Yoon, S.-M. Ha, S. Kwon et al., "Introducing EzBioCloud: a taxonomically united database of $16 \mathrm{~S}$ rRNA gene sequences and whole-genome assemblies," International Journal of Systematic and Evolutionary Microbiology, vol. 67, no. 5, pp. 1613-1617, 2017.

[35] L. Karthik, G. Kumar, A. V. Kirthi, A. A. Rahuman, and K. V. Bhaskara Rao, "Streptomyces sp. LK3 mediated synthesis of silver nanoparticles and its biomedical application," Bioprocess and Biosystems Engineering, vol. 37, no. 2, pp. 261-267, 2014.

[36] Y. K. Mohanta and S. K. Behera, "Biosynthesis, characterization and antimicrobial activity of silver nanoparticles by Streptomyces sp. SS2," Bioprocess and Biosystems Engineering, vol. 37, no. 11, pp. 2263-2269, 2014.

[37] N. E.-A. El-Naggar, N. A. M. Abdelwahed, and O. M. M. Darwesh, "Fabrication of biogenic antimicrobial silver nanoparticles by Streptomyces aegyptia NEAE 102 as eco-friendly nanofactory," Journal of Microbiology and Biotechnology, vol. 24, no. 4, pp. 453-464, 2014.

[38] S. A. Ibrahim, S. K. Abd-El-Aal, A. AG, and M. A. El-Sayd, "Molecular identification and characterization of some gluconacetobacter strains isolated from some Egyptian fruits," Research Journal of Pharmaceutical, Biological and Chemical Sciences, vol. 5, no. 4, pp. 1617-1627, 2014.

[39] M. Kontro, U. Lignell, M.-R. Hirvonen, and A. Nevalainen, "pH effects on 10 Streptomyces spp growth and sporulation depend on nutrients," Letters in Applied Microbiology, vol. 41, no. 1, pp. 32-38, 2005.

[40] J. Yang, Z. Yang, Y. Yin, M. Rao, Y. Liang, and M. Ge, "Three novel polyene macrolides isolated from cultures of Streptomyces lavenduligriseus," The Journal of Antibiotics, vol. 69, no. 1, pp. 62-65, 2015.

[41] A. Sarmiento-Vizcaíno, A. F. Braña, V. González et al., "Atmospheric dispersal of bioactive Streptomyces albidoflavus strains among terrestrial and marine environments," Microbial Ecology, vol. 71, no. 2, pp. 375-386, 2015.

[42] J. Y. Lee, J. Y. Lee, H. W. Jung, and B. K. Hwang, "Streptomyces koyangensis sp. nov., a novel actinomycete that produces 4-phenyl-3-butenoic acid," International Journal of Systematic and Evolutionary Microbiology, vol. 55, no. 1, pp. 257-262, 2005.

[43] M. Kulkarni, S. Gorthi, G. Banerjee, and P. Chattopadhyay, "Production, characterization and optimization of actinomycin D from Streptomyces hydrogenans IB310, a (n antagonistic bacterium against phytopathogens," Biocatalysis and Agricultural Biotechnology, vol. 10, pp. 69-74, 2017. 
[44] S. M. Pimentel-Elardo, S. Kozytska, T. S. Bugni, C. M. Ireland, H. Moll, and U. Hentschel, "Anti-parasitic compounds from Streptomyces sp. strains isolated from Mediterranean sponges," Marine Drugs, vol. 8, no. 2, pp. 373-380, 2010.

[45] P. Caffrey, S. Lynch, E. Flood, S. Finnan, and M. Oliynyk, "Amphotericin biosynthesis in Streptomyces nodosus: deductions from analysis of polyketide synthase and late genes," Chemistry \& Biology, vol. 8, no. 7, pp. 713-723, 2001.

[46] P. Sweeney, C. D. Murphy, and P. Caffrey, "Exploiting the genome sequence of Streptomyces nodosus for enhanced antibiotic production," Applied Microbiology and Biotechnology, vol. 100, no. 3, pp. 1285-1295, 2016.

[47] T. M. Nguyen and J. Kim, "Description of Streptomyces fabae sp. nov., a producer of antibiotics against microbial pathogens, isolated from soybean (Glycine max) rhizosphere soil," International Journal of Systematic and Evolutionary Microbiology, vol. 65, no. Pt_11, pp. 4151-4156, 2015.

[48] H. Matsuo, Y. Kondo, T. Kawasaki, and N. Imamura, "Cineromycin B isolated from Streptomyces cinerochromogenes inhibits adipocyte differentiation of 3T3-L1 cells via Krüppel-like factors 2 and 3," Life Sciences, vol. 135, pp. 35-42, 2015. 